\title{
What Makes Eye Contact Special? Neural Substrates of On-Line Mutual Eye-Gaze: A Hyperscanning fMRI Study
}

[DTakahiko Koike, ${ }^{1,2}$ Motofumi Sumiya, ${ }^{1,2}$ Eri Nakagawa, ${ }^{1}$ Shuntaro Okazaki, ${ }^{1}$ and ${ }^{\circledR}$ Norihiro Sadato ${ }^{1,2,3}$

https://doi.org/10.1523/ENEURO.0284-18.2019

${ }^{1}$ Division of Cerebral Integration, Department of System Neuroscience, National Institute for Physiological Sciences (NIPS), Aichi 444-8585, Japan, ${ }^{2}$ Department of Physiological Sciences, School of Life Sciences, The Graduate University for Advanced Studies (SOKENDAI), Hayama 240-0193, Japan, and ${ }^{3}$ Biomedical Imaging Research Center (BIRC), University of Fukui, Fukui 910-1193, Japan

\section{Visual Abstract}

\section{Hyperscanning fMRI}

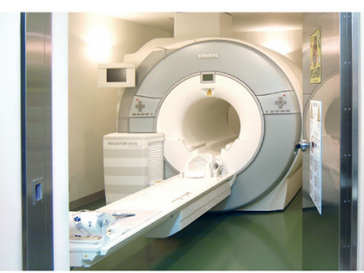

LIVE condition

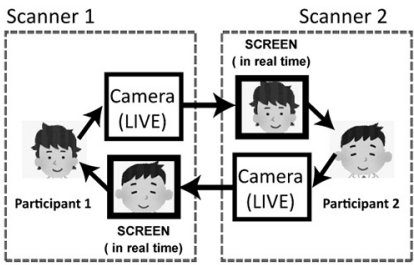

REPLAY condition

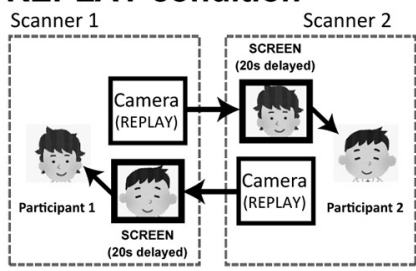

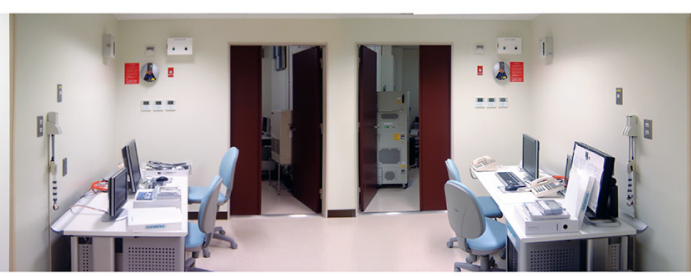

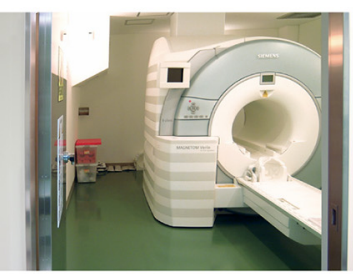

Inter-brain synchronization

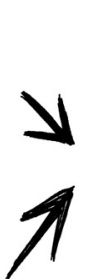

LIVE - REPLAY $\rightarrow$
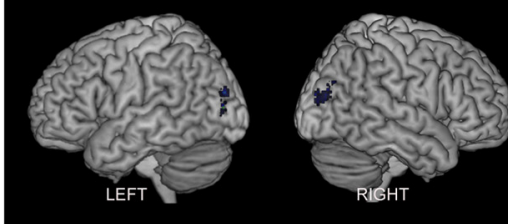

\section{Activation}

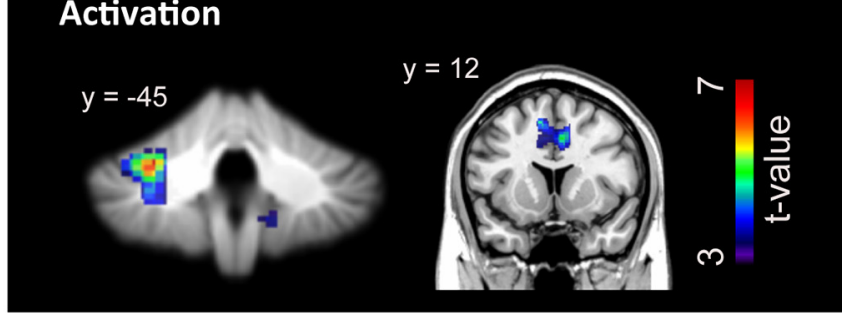

\section{Significance Statement}

Eye contact is a key element that connects humans during social communication. We focused on a previously unaddressed characteristic of eye contact: real-time mutual interaction as a form of automatic mimicry. Our results indicate that real-time interaction during eye contact is mediated by the cerebellum and limbic mirror system. These findings underscore the importance of the mirror system and cerebellum in real-time unconscious social interaction. 
Automatic mimicry is a critical element of social interaction. A salient type of automatic mimicry is eye contact characterized by sharing of affective and mental states among individuals. We conducted a hyperscanning functional magnetic resonance imaging study involving on-line (LIVE) and delayed off-line (REPLAY) conditions to test our hypothesis that recurrent interaction through eye contact activates the limbic mirror system, including the anterior cingulate cortex (ACC) and anterior insular cortex (AIC), both of which are critical for self-awareness. Sixteen pairs of human adults participated in the experiment. Given that an eye-blink represents an individual's attentional window toward the partner, we analyzed pairwise time-series data for eye-blinks. We used multivariate autoregression analysis to calculate the noise contribution ratio (NCR) as an index of how a participant's directional attention was influenced by that of their partner. NCR was greater in the LIVE than in the REPLAY condition, indicating mutual perceptual-motor interaction during real-time eye contact. Relative to the REPLAY condition, the LIVE condition was associated with greater activation in the left cerebellar hemisphere, vermis, and ACC, accompanied by enhanced functional connectivity between ACC and right AIC. Given the roles of the cerebellum in sensorimotor prediction and ACC in movement initiation, ACC-cerebellar activation may represent their involvement in modulating visual input related to the partner's movement, which may, in turn, involve the limbic mirror system. Our findings indicate that mutual interaction during eye contact is mediated by the cerebellum and limbic mirror system.

Key words: automatic mimicry; eye contact; fMRI; mirror neurons; shared attention

\section{Introduction}

Automatic mimicry refers to unconscious or automatic imitation of movement (Prochazkova and Kret, 2017). It is a critical part of human social interaction because it is closely tied to the formation of relationships and feeling of empathy (Chartrand and van Baaren, 2009). Automatic mimicry occurs when two or more individuals engage in the same behavior within a short window of time (e.g., facial expressions, body postures, laughter, yawning; Prochazkova and Kret, 2017). Automatic mimicry induces synchronous behavior through recurrent interaction (Okazaki et al., 2015), thereby enabling spontaneous synchronization (e.g., clapping) and goal-directed cooperation (Sebanz et al., 2006).

Eye contact is one of the most salient types of automatic mimicry, as two people must be able to synchronize their eye movements to make eye contact (Prochazkova and Kret, 2017). Eye gaze provides a communicative signal that transfers information regarding emotional and mental states (Emery, 2000). Eye contact, or mutual gaze, conveys the message, "I am attending to you," thereby

Received July 12, 2018; accepted February 5, 2019; First published February 25, 2019

The authors declare no competing financial interests.

Author contributions: T.K. and N.S. designed research; T.K., M.S., E.N., and S.O. performed research; T.K. analyzed data; T.K. and N.S. wrote the paper; S.O. contributed unpublished reagents/analytic tools.

This study was supported by Japan Society for the Promotion of Science (JSPS) Grant-in-Aid for Scientific Research (KAKENHI) \#15H01846 to N.S.; Ministry of Education, Culture, Sports, Science and Technology KAKENHI \#15K12775, JSPS KAKENHI \#18H04207, and JSPS KAKENHI \#15H05875 to T.K.; and JSPS KAKENHI \#16K16894 to E.N. This research is partially supported by the Strategic Research Program for Brain Sciences from Japan Agency for Medical Research and Development (AMED) under Grant JP18dm0107152 and by the HAYAO NAKAYAMA Foundation for Science \& Technology and Culture.

Correspondence should be addressed to Norihiro Sadato at sadato@nips.ac.jp. https://doi.org/10.1523/ENEURO.0284-18.2019

Copyright (C) 2019 Koike et al.

This is an open-access article distributed under the terms of the Creative Commons Attribution 4.0 International license, which permits unrestricted use, distribution and reproduction in any medium provided that the original work is properly attributed. promoting effective communication and enhancing social interaction (Farroni et al., 2002; Schilbach, 2015).

Recent functional magnetic resonance imaging (fMRI) studies have revealed that eye contact activates the social brain, including the fusiform gyrus (George et al., 2001; Calder et al., 2002; Pageler et al., 2003), anterior superior temporal gyri (Calder et al., 2002; Wicker et al., 2003), posterior superior temporal gyri (Pelphrey et al., 2004; Schilbach et al., 2006; Conty et al., 2007), medial prefrontal cortex (Calder et al., 2002; Kampe et al., 2003; Schilbach et al., 2006; Conty et al., 2007), orbitofrontal cortex (Wicker et al., 2003; Conty et al., 2007), and amygdala (Kawashima et al., 1999; Wicker et al., 2003; Sato et al., 2004; for review, see Senju and Johnson, 2009). The above-mentioned studies were conducted using singleparticipant fMRI data, contrasting the neural activation elicited by an eye-contact event with that elicited by an eye-aversion event. However, neural substrates underlying recurrent interaction during eye contact that result in the development of shared, pair-specific psychological states (e.g., attention and emotion) remain unknown.

The mirror neuron system plays a role during mutual interaction through joint attention (Saito et al., 2010; Koike et al., 2016). The existence of two main networks with mirror properties has been demonstrated, with one residing in the parietal lobe and premotor cortex plus caudal part of the inferior frontal gyrus (parietofrontal mirror system), and the other formed by the insula and anterior medial frontal cortex (limbic mirror system; Cattaneo and Rizzolatti, 2009). The parietofrontal mirror system is involved in recognizing voluntary behavior, while the limbic mirror system is devoted to recognizing affective behavior (Cattaneo and Rizzolatti, 2009). We hypothesized that mutual interaction involving eye contact activates the limbic mirror system.

This study aimed to elucidate the behavioral and neural representations of mutual interaction during eye contact using hyperscanning fMRI (Koike et al., 2016). The neural activity associated with real-time eye contact was compared with that of non-real-time eye contact using a 
double-video system (Murray and Trevarthen, 1985). Eye contact is characterized by a two-way, behavioral stimulus-to-brain coupling, such that the behavior of a partner is coupled to the activation in the brain of the other (Hari and Kujala, 2009). Thus, face-to-face interaction through eye contact can be regarded as a mirrored reactive-predictive controller system consisting of two controllers (Wolpert et al., 2003). We used eye-blink as a behavioral index of mutual exchange of communicative cues between two participants during eye contact. As the blinks of others can be easily recognized due to their relatively long duration (200-400 ms; VanderWerf et al., 2003), eye-blinks can provide social communication cues (Nakano and Kitazawa, 2010). Further, blink rates change with internal states such as arousal, emotion, and cognitive load (Ponder and Kennedy, 1927; Hall, 1945; Stern et al., 1984). Finally, the timing of eye-blinks is associated with implicit (Herrmann, 2010) and explicit (Orchard and Stern, 1991) attentional pauses in task content. Nakano and Kitazawa (2010) observed that eye-blinks of a listener and speaker were synchronized during face-to-face conversations, and concluded that eye-blinks define the attentional temporal window and that its synchronization reflects smooth communication between interactants through sharing of attention in the temporal domain. In this study, we used hyperscanning fMRI to analyze brain activation related to eye-blinks using the following different measures: activation, modulation of functional connectivity, and interbrain synchronization.

\section{Materials and Methods}

\section{Participants}

Thirty-four volunteers participated in the experiment (20 men, 14 women; mean age $\pm \mathrm{SD}, 21.8 \pm 2.12$ years). Participant pairs were determined before the experiment and consisted of participants of the same sex. None of the participants had met each other before the experiment. All participants except one were right handed, as evidenced by the Edinburgh Handedness Inventory (Oldfield, 1971). None of the participants had a history of neurologic or psychiatric illness. The protocol was approved by the ethics committee of the National Institute for Physiological Sciences. The study was conducted in compliance with the national legislation and the Code of Ethical Principles for Medical Research Involving Human Subjects of the World Medical Association (Declaration of Helsinki). All participants provided written informed consent before the experiment.

\section{Design and Procedure \\ Experimental setup}

To measure neural activation during the on-line exchange of eye signals between pairs of participants, we used a hyperscanning paradigm with two MRI scanners (Magnetom Verio 3T, Siemens) installed side-by-side in parallel, sharing one control room and a triggering system (Morita et al., 2014; Koike et al., 2016). The top component of the standard 32-channel coil was replaced by a small four-channel flex coil (Siemens) attached with a special holding fixture (Takashima Seisakusho; Morita et al., 2014; Koike et al., 2016) to fully visualize the eye region. On-line grayscale video cameras were used during scanning to identify reciprocal face-to-face interaction (NAC Image Technology). The cameras captured images of each participant's face, including the eyes and eyebrows. The captured images were in turn projected using a liquid crystal display projector (CP-SX12000J, Hitachi) onto a half-transparent screen that stood behind the scanner bed. The captured images were also entered into the picture delay system (VM-800, Sugioka System), which could output video delayed by an arbitrary amount of time. For analysis, video pictures used in the experiment were transferred to a video recording system ( $\mathrm{Pa}$ nasonic). We recorded facial movement in AVI (audio video interleave) format $(640 \times 480$ pixels, 30 frames $/ \mathrm{s})$. While the exact values varied depending on the participant's head size, the screen stood $\sim 190 \mathrm{~cm}$ from the participants' eyes, and the stimuli were presented at a visual angle of $13.06^{\circ} \times 10.45^{\circ}$. The delay between the capture and projection of the participants' face was controlled using a hardware device (VM-800, Ito Co., Ltd.) connected between the video camera and projector. The delay was set at $20 \mathrm{~s}$ for the REPLAY condition and $0 \mathrm{~s}$ for the LIVE condition. The intrinsic delay of the on-line video system in this experimental setup was $\sim 100 \mathrm{~ms}$.

\section{Experimental conditions}

We adopted a conventional blocked design for this study. Each run included three conditions: LIVE, REPLAY, and REST. During the LIVE condition, participants were presented with a live video of their partner's face in real time (Fig. 1B), allowing for the on-line exchange of information between the two participants. We instructed participants to gaze into the right or left eye of their partners and think about their partner as follows: what he/she is thinking about, what is his/her personality, how he/she is feeling. The participants were instructed not to exhibit explicit facial expressions such as laughing or grimacing. We also informed them that we will stop MRI scanning if they were not gazing into the partner's eyes for an extended period of time. The REPLAY condition was identical to the LIVE condition, except that the participant watched a video picture of their partner's face presented at a delay of $20 \mathrm{~s}$. Therefore, there was no real-time interaction between the participants (Fig. 1C). During the REPLAY condition, the participant was informed that all the videos they were watching represented their partner's face in real time. During the REST condition (baseline), participants were required to gaze at the blank screen (Fig. 1A). Although we monitored the participants to ensure that they do not fall asleep, two participants fell asleep during the experiment, and we had to restart the experiment after a short break.

Before starting the run, a live video of the partner was presented on the screen to confirm that an interactive partner was in the other scanner. Following confirmation, the video was turned off. The first run began with the REST condition for $30 \mathrm{~s}$, followed by the LIVE, REPLAY, and REST conditions for $20 \mathrm{~s}$ each. After each $20 \mathrm{~s}$ presentation of the partner's face, the screen was turned off for $1 \mathrm{~s}$, and the condition was switched (e.g., from LIVE 


\section{A LIVE condition}

Scanner 1

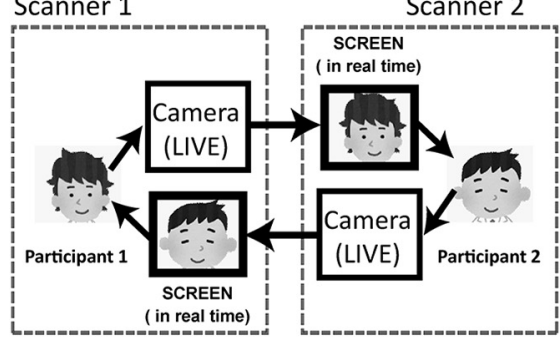

B REPLAY condition



C REST condition

Scanner 1

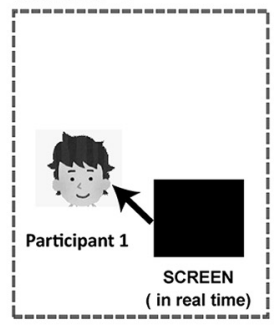

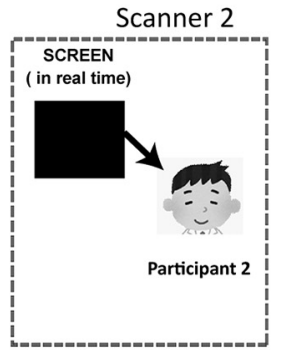

\section{Timecourse of experiment}

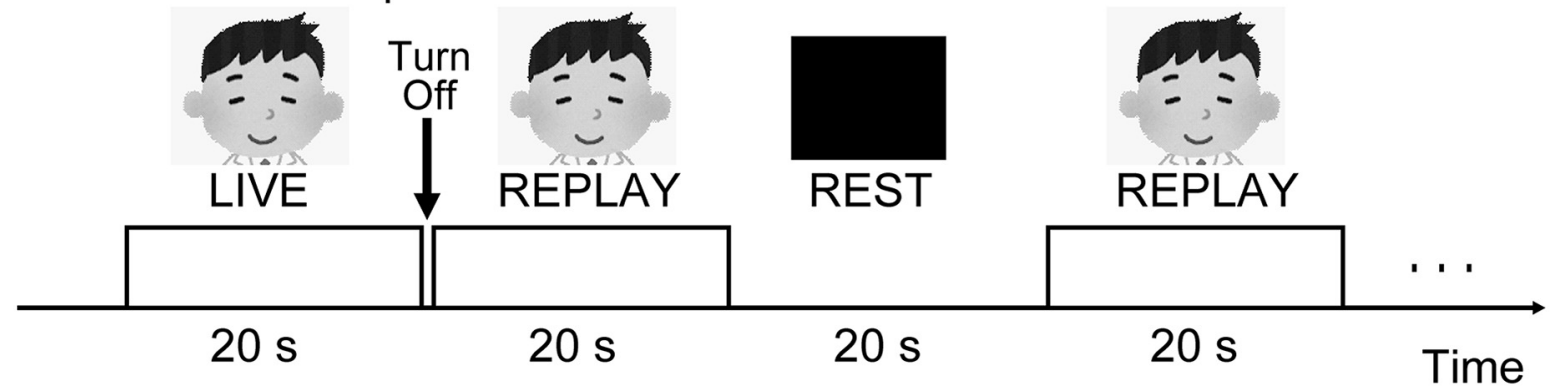

Figure 1. Experimental setup. A, LIVE condition: the face of Participant 1 is projected on the screen of Participant 2 in real time and vice versa, allowing a mutual exchange of information. $\boldsymbol{B}$, REPLAY condition: the picture is projected on the screen with a $20 \mathrm{~s}$ delay; therefore, there is no mutual interaction between participants in real time. $\boldsymbol{C}$, REST condition (baseline): no image is presented on the black screen. $\boldsymbol{D}$, Sequence of presentation of the experimental conditions.

to REPLAY, REPLAY to REST; Fig. 1D). The $1 \mathrm{~s}$ interval was designed to prevent participants from becoming aware of the difference between the LIVE and REPLAY conditions. The order of presenting the conditions was pseudorandomized. The conditions were switched manually during the fMRI run according to a predefined experimental design. Each run consisted of eight LIVE and eight REPLAY conditions. The total length of each run was $8 \mathrm{~min}$ and $30 \mathrm{~s}$, and the entire scan consisted of four runs. Throughout the experiment, none of the participants exhibited any sudden display of emotions such as laughter.

An interview following the experiment revealed that only one female pair realized that a delayed facial picture was presented in one of the conditions during the experiment; thus, the requirements of the experiment were not fulfilled in the pair. Data were analyzed from the remaining 32 participants (20 men, 12 women; mean \pm SD age, $21.8 \pm$ 2.03 years).

\section{MRI data acquisition}

Brain activation data were acquired using interleaved T2*-weighted, gradient echo, echoplanar imaging (EPI) sequences. Volumes consisted of 60 axial slices, each 2.0 $\mathrm{mm}$ thick with a $0.5 \mathrm{~mm}$ gap, covering the entire cerebral cortex and cerebellum. The time interval between two successive acquisitions of the same image [repetition time (TR)] was $1000 \mathrm{~ms}$, with a flip angle of $80^{\circ}$ and echo time (TE) of $30 \mathrm{~ms}$. The field of view (FOV) was $192 \mathrm{~mm}$, and the in-plane matrix size was $64 \times 64$ pixels. We used the multiband accelerated sequence developed at the University of Minnesota (Moeller et al., 2010), with the multiband factor set to 6 . Thus, 510 volumes $(8 \mathrm{~min}$ and $30 \mathrm{~s}$ ) were collected for each run. For anatomic reference,
T1-weighted high-resolution images were obtained using a three-dimensional magnetization-prepared rapid acquisition gradient echo (MPRAGE) sequence (TR = $1800 \mathrm{~ms}$; $\mathrm{TE}=2.97 \mathrm{~ms} ; \mathrm{FA}=9^{\circ} ; \mathrm{FOV}=256 \mathrm{~mm}$; voxel dimensions $=1 \times 1 \times 1 \mathrm{~mm}^{3}$ ) and a full 32-channel phased array coil.

\section{Data analysis}

Behavioral data analysis

Extraction of eye-blink time series Eye-blink was chosen as a behavioral index of interaction during mutual gaze (Koike et al., 2016). We calculated the "motion energy" using the AVI video of the participant's face during the task (Schippers et al., 2010) to evaluate the time series of eye-blinks. Due to technical difficulties with the video recording system, data from two pairs were unavailable. In total, video data of faces from 14 pairs (18 men, 10 women; mean \pm SD age, $21.8 \pm 2.17$ years) were subjected to the analysis described below.

Figure 2 illustrates the procedure used to calculate the motion energy time series representing eye-blinks. First, the spatial window $(400 \times 100$ pixels) of the AVI video was manually set to cover the eye area of each participant. Second, using the pixel intensity of the defined eye area, we obtained the motion energy index, which can detect the occurrence of motion only from a series of pictures (Schippers et al., 2010). The first-order difference in picture intensity was calculated frame by frame in each pixel, and the average of the absolute value of differences in each frame was calculated. This process was used to obtain motion energy values at specific time points. The calculation was repeated to obtain the motion energy time series reflecting eye-blinks during each run. Third, we 


\section{Frame $\mathrm{N}$ \\ Frame $\mathrm{N}+1$

Frame $\mathrm{N}$
minus
Frame $\mathrm{N}+1$
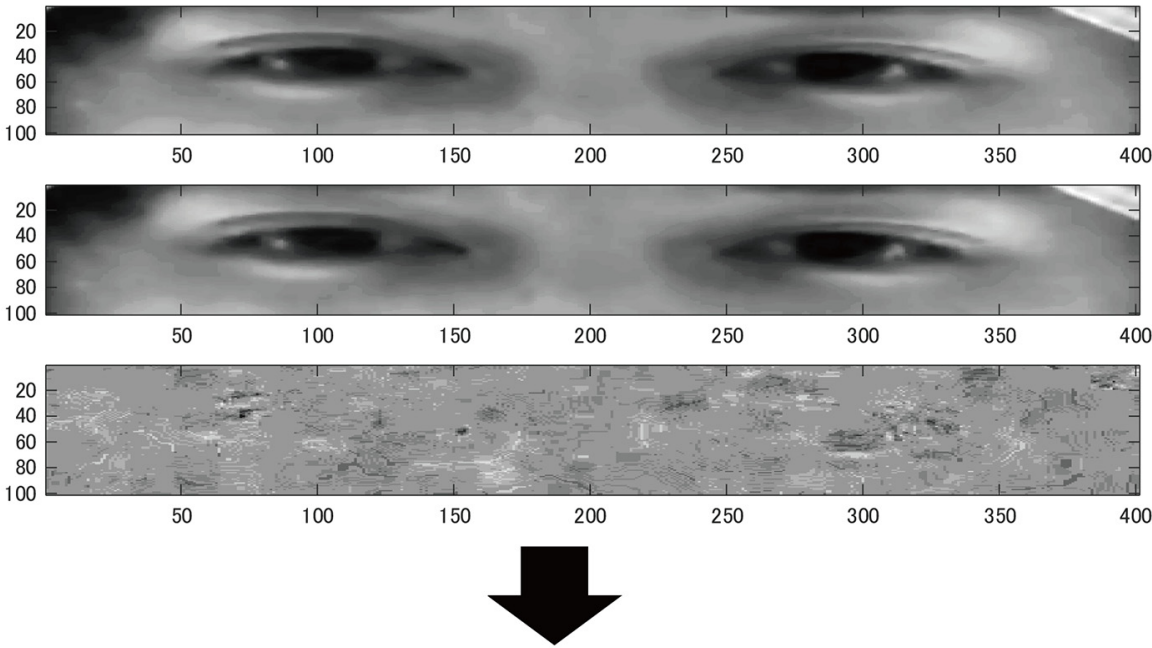

Absolute value, Average all pixels

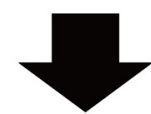

Motion energy time series
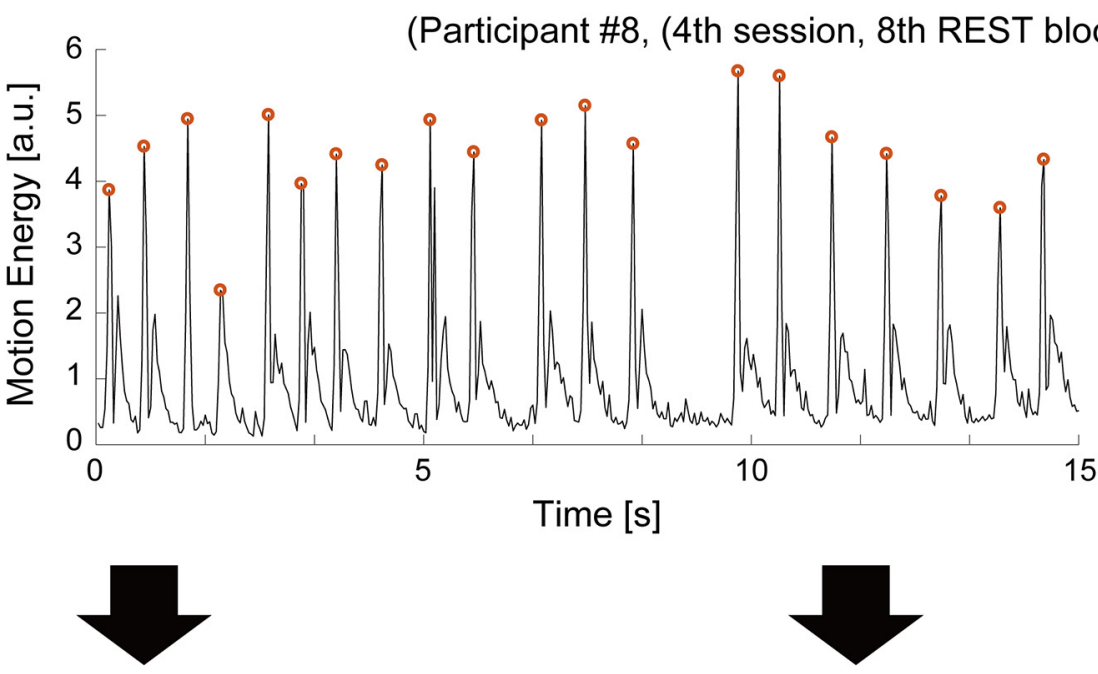

Akaike Causality Analysis

Eye-blink counting

Figure 2. Evaluation of the motion energy time series representing eye-blinks. The red dots indicate the timing of the detected eye-blink.

divided the time series in each run into shorter subsections corresponding to the LIVE, REPLAY, and REST conditions. Although each condition lasted $20 \mathrm{~s}$ (Fig. 1D), we analyzed only the final $15 \mathrm{~s}$ of each condition to minimize the effect of brightness instability (largely due to the procedure for switching conditions). We obtained eight time series for each condition of a single run. As each participant underwent four runs, 32 time series were obtained for each condition per participant. Finally, the effect of the linear trend in the data was removed using the "detrend" function implemented in MATLAB. The whole procedure was performed using a MATLAB script (MATLAB 14, MathWorks) developed in-house.

Number of eye-blinks To determine whether the number of eye-blinks itself was influenced by differences in the type of task, we calculated the number of eye-blinks in the LIVE, REPLAY, and REST conditions using the extracted time series of motion energy. We first adapted the peak-detection function implemented in MATLAB, which automatically detected and marked the time point at which the eye-blink appeared to occur (Fig. 2). Next, we visually examined whether the detected time point was acceptable. Finally, we calculated the average number of eye-blinks in 1 block (15 s) for each participant. All calculations were performed using a MATLAB script (MATLAB 2014) developed in-house.

Causality analysis between eye-blink time series Several hyperscanning studies have used synchronization or correlation as an index of interaction (Koike et al., 2016), neither of which can evaluate the directional effect. In this 
study, we used an Akaike causality model (Akaike, 1968; Ozaki, 2012), which can delineate the causal direction and quantify its effect. The Akaike causality model uses a multivariate autoregressive (MVAR) model under the steady-state assumption and can quantify the proportion of the power-spectral density of an observed variable from the independent noise of another variable. The quantified causality, that is, the noise contribution ratio (NCR) index, is regarded as a measure of how one variable is influenced by another. In this study, we assumed that the eye-blink time series satisfies a steady-state assumption at least in one block. The NCR values were calculated as follows.

First, an MVAR model was applied to a pair of timeseries data, $x(t)$ and $y(t)$, using the linear sum of the history of the two time series, as follows:

$$
\begin{aligned}
& x(t)=\sum_{i=1}^{N} a_{i} x(t-i)+\sum_{i=1}^{N} b_{j} y(t-i)+u_{x}(t) \\
& y(t)=\sum_{i=1}^{N} c_{i} x(t-i)+\sum_{i=1}^{N} d_{i} y(t-i)+u_{y}(t),
\end{aligned}
$$

where the time series $x(t)$ and $y(t)$ correspond to the time series of the participant's eye-blinks and that of the partner, respectively. In these equations, $a_{i}, b_{i}, c_{i}$, and $d_{i}$ indicate AR coefficients, while $u_{x}$ and $u_{y}$ indicate the residual noise in the eye-blinks of the participant and partner, respectively. The AR order $N$ defines the duration of the history. For each pair of time-series data, the AR order $N$ was estimated to minimize the Akaike information criterion in the range from 1 to 10 . Next, we estimated the power spectrum of the two time series based on the sum of the contributions of the $x$-specific noise (i.e., $\mid \alpha$ $\left.(f) \mid{ }^{2} \sigma_{u x}{ }^{2}\right)$ and $y$-specific noise (i.e., $\left.|\beta(f)|{ }^{2} \sigma_{u y}{ }^{2}\right)$. Here, $\mid \alpha$ $(f) \mid$ and $|/ 2(f)|$ are frequency response functions, derived from Fourier transformation via an impulse response function, using a set of AR coefficients, while $\sigma_{u x}$ and $\sigma_{u x}$ indicate the variance of residual noise $u_{x}$ and $u_{y}$, respectively. The $N C R_{y \rightarrow x}(f)$, an index reflecting how the participant's eye-blinks $x(t)$ are influenced by the partner's eyeblinks $y(t)$, was calculated from the ratio of part of the spectral density of $x(t)$ contributed by $\sigma_{u y}{ }^{2}$ to the total spectral density of $x(t)$ at frequency $f$. Therefore, $N C R_{y \rightarrow x}$ $(f)$ can be expressed as follows:

$$
N C R_{y \rightarrow x}(f)=\frac{|\beta(f)|^{2} \sigma_{u y}{ }^{2}}{|\alpha(f)|^{2} \sigma_{u x}{ }^{2}+|\beta(f)|^{2} \sigma_{u y}{ }^{2}} .
$$

To assess how $x(t)$ is influenced by $y(t)$ across the whole frequency range, we mathematically integrated NCR values via trapezoidal numerical integration as follows:

$$
\Sigma N C R_{y \rightarrow x}=\int_{0}^{f_{s} / 2} N C R_{y \rightarrow x}(f) d f,
$$

where $f_{s}$ is the sampling frequency of the time series $x$ $(t)$ and $y(t)$. In this study, $f_{s}$ was $30 \mathrm{~Hz}$, based on the frame rate of the video data. We collected 32 time series for each condition. Therefore, our calculations yielded 32 $\Sigma N C R$ values for each condition per participant. These $32 \Sigma$ NCR values were averaged to calculate one summarized $\Sigma N C R$ value for each participant in each condition. Using the summarized $\Sigma$ NCR, we applied statistical analyses to determine whether the influence of the partner differed between conditions. The entire procedure was performed using a MATLAB script (MATLAB 2014) written in-house.

In this study, we calculated four $\Sigma$ NCR values to assess how a participant's eye-blink was influenced by that of the partner. Firstly, in the REST condition, participants could see nothing on the screen. Therefore, the $\Sigma N C R$ value in the REST condition (i.e. $\Sigma N N_{F \rightarrow F}^{R E S T}$ ) was regarded as a baseline of causal relationship. In the LIVE condition, the face of one participant was immediately projected on the screen, and the partner was able to see the face in real time. In this condition, we calculated $\Sigma$ NCR between two participants' time series (i.e., $\Sigma N C R_{F \rightarrow F}^{L I V E}$ ). The $\Sigma N C R$ value represents how participants influence their partners when they mutually interact with each other in real time. Next, in the REPLAY condition, two types of causality were calculated as follows: first, the $\Sigma$ NCR value between actual eye-blinks, like in the LIVE condition (i.e., $\Sigma N \mathrm{NCR}_{F \rightarrow F}^{R E P L A Y}$ ); and second, the $\Sigma N C R$ value in the REPLAY condition representing how the eye-blinks projected on the screen has an influence on the actual eye-blink time series, $\Sigma N C R_{S \rightarrow F}^{R E P L A}$. While it is possible that a participant's face receives influence from the delayed picture on the screen (Nakano and Kitazawa, 2010), influence from an actual eye-blink to the screen (reverse influence) is theoretically absent. We also calculated the $\Sigma N C R$ value (i.e., $\Sigma N C R_{F \rightarrow F}^{R E S T}$ ). It represents how participants are influenced by a video picture, while there could be only unidirectional influence from the screen to actual eye-blinks.

Estimation of statistical inferences and data visualization All statistical inference estimation for the behavioral data analysis was performed using R (RRID:SCR_001905). We analyzed three types of behavioral measures. (1) The number of eye-blinks is highly influenced by the degree of attention (Ponder and Kennedy, 1927; Hall 1945; Stern et al., 1984; Orchard and Stern, 1991; Herrmann, 2010) and could reflect the differences across conditions. We tested the number of eye-blinks in three conditions using repeated-measures analysis of variance (ANOVA). (2) $\Sigma$ NCR values: we have four $\Sigma N C R$ values for each participant, $\Sigma N C R_{F \rightarrow F}^{R E S T}$ in the REST condition, $\Sigma N C R_{F \rightarrow F}^{R E P L A Y}$ and $\Sigma N C R_{S \rightarrow F}^{R E P L A Y}$ in the REPLAY condition, and $\Sigma N C R_{F \rightarrow F}^{L I V E}$ in the LIVE condition. The differences between them were assessed using repeatedmeasures ANOVA. (3) Enhanced $\Sigma N C R$ values: in the REST condition, participants know there is no interaction with a partner as nothing is projected on the screen. Therefore, theoretically speaking, the REST condition could be regarded as a baseline condition. We calculated the increase in $\Sigma N C R$ values (enhancement) by subtracting the $\Sigma N C R R_{F \rightarrow F}^{R E S T}$ value from each of the $\Sigma N C R$ values. Thus, we have three enhanced $\Sigma N C R$ values for each participant: $\sum N_{C R} R_{F \rightarrow F}^{L I V E}-\sum N \mathrm{NCR}_{F \rightarrow F}^{R E S T}, \quad \sum \mathrm{NCR}_{F \rightarrow F}^{R E P A Y}-\sum \mathrm{NCR}_{F \rightarrow F}^{R E S T}$, and $\Sigma N N_{S \rightarrow F}^{R E P L A Y}-\Sigma N N_{F \rightarrow F}^{L I N E}$. . Repeated-measures ANOVA was used to test the differences between these values. In all 
ANOVA procedures, the effect size was measured using the generalized $\eta^{2}$ value (Olejnik and Algina, 2003). In the post hoc pairwise analysis, estimated $p$ values were adjusted using a Bonferroni correction. The confidence levels for post hoc pairwise analyses were calculated via the pairwise confidence intervals of Franz and Loftus (2012). The details of the statistical methods used in this behavioral data analysis are listed in Table 1. All the graphs were prepared using the RainCloudPlots R-script (Allen et al., 2018; https://github.com/RainCloudPlots/RainCloudPlots), which could provide a combination of box, violin, and dataset plots. In the dataset plot, each dot represents a data point, respectively. Outliers were defined by 2 SDs and are represented in Figure 2 by red diamonds. In the boxplot, the line dividing the box represents the median of the data, while the ends of the box represent the upper and lower quartiles. The extreme lines show the highest and lowest values excluding outliers defined by 2.0 SDs.

Neuroimaging analysis

Image preprocessing The first 10 volumes $(10 \mathrm{~s})$ of each fMRI run were discarded to allow for stabilization of the magnetization, and the remaining 500 volumes/run (total of 2000 volumes/participant) were used for the analysis. The data were analyzed using statistical parametric mapping (SPM12, Wellcome Trust Center for Neuroimaging, London, UK; RRID:SCR_007037) implemented in MATLAB 2014 (RRID:SCR_001622). All volumes were realigned for motion correction. The whole-head T1-weighted high-resolution MPRAGE volume was coregistered with the mean EPI volume. The T1-weighted image was normalized to the Montreal Neurologic Institute (MNI) template brain using a nonlinear basis function in SPM12. The same normalization parameters were applied to all EPI volumes. All normalized EPI images were spatially smoothed in three dimensions using a Gaussian kernel (full-width at half-maximum $=8$ $\mathrm{mm}$ ).

Estimation of task-related activation using univariate generalized linear modeling Because of technical difficulties, we could not acquire fMRI data from one pair. Therefore, we analyzed whole fMRI data acquired from 30 participants (18 men, 12 women; mean \pm SD age, $21.7 \pm 2.10$ years). Statistical analysis was conducted at two levels. First, individual task-related activation was evaluated. Second, summary data for each participant were incorporated into a second-level analysis using a randomeffects model (Friston et al., 1999) to make inferences at a population level.

In the individual-level analysis, the blood oxygenation level-dependent (BOLD) time series representing the brain activation of each participant was first modeled using a boxcar function convolved with a hemodynamic response function and filtered using a high-pass filter (128 s), while controlling for the effect of runs. Serial autocorrelation assuming a first-order autoregressive model was estimated from the pooled active voxels using the restricted maximum likelihood procedure and used to whiten the data (Friston et al., 2002). No global scaling was applied. The model parameters were estimated using the leastsquares algorithm on the high pass-filtered and whitened data and design matrix. Estimates for each of the model parameters were compared with the linear contrasts to test hypotheses regarding region-specific condition effects. Next, the weighted contrasts of the parameter estimate (i.e., LIVE > REST and REPLAY > REST) in the individual analyses were incorporated into the group analysis. Contrast images obtained via individual analyses represented the normalized task-related increment of the MR signal relative to the control condition (i.e., the REST condition) for each participant.

In the group-level analysis, we investigated differences in brain activation between the LIVE and REPLAY conditions using these contrast images and the random-effects model implemented in SPM12. We analyzed these data using the paired $t$ test. The resulting set of voxel values for each contrast constituted a statistical parametric map of the $t$ statistic (SPM $\{t\}$ ). The threshold for significance of the SPM $\{t\}$ was set at $p<0.05$ with familywise error (FWE) correction at the cluster level for the entire brain (Friston et al., 1996). To control FWE rates using random field theory (Eklund et al., 2016), the height threshold was set at an uncorrected $p$ value $<0.001$, which is conservative enough to depict cluster-level inference with the parametric procedure (Flandin and Friston, 2017). To validate the statistical inference with a parametric method, we also tested the statistical significance of activation using a nonparametric permutation test implemented in the SnPM13 toolbox (RRID:SCR_002092; Nichols and Holmes, 2002). We used the nonparametric paired $t$ test with no variance smoothing; the number of permutations was set at 10,000 . The SnPM toolbox did not yield statistical significance at all the voxels reported in SPM; thus, the $p$ values for some voxels have not been listed in the tables.

Generalized psychophysiologic interaction analysis Next, we performed generalized psycho-physiologic interaction (gPPI) analysis (Friston et al., 1997; McLaren et al., 2012) using the CONN toolbox (Whitfield-Gabrieli and NietoCastanon, 2012; RRID:SCR_009550) to reveal how effective connectivity from the LIVE- or REPLAY-specific regions (toward other brain regions) was altered between the LIVE and REPLAY conditions. For this purpose, we selected three clusters based on the LIVE $>$ REPLAY contrast defined by the results of univariate generalized linear modeling (GLM) analysis (Fig. 3, Table 2) as seed regions for the gPPI analysis. We used conventional seedto-voxel gPPI analysis in which the whole brain is the search area. The components associated with a linear trend, CSF, white matter (WM), and experimental tasks (i.e., LIVE and REPLAY effects) were removed from the BOLD time series as confounding signals. Using the residual time series, gPPI analysis was performed to evaluate whether the effective connectivity from the seed region was modulated by the task condition (i.e., the LIVE or REPLAY condition) at the individual level. This individual-level analysis produced contrast images representing the modulation of effective connectivity from the seed region. Up to this point, all procedures were conducted using the CONN toolbox. Finally, we used these contrast images and the random-effect model implemented in SPM12 to test whether any regions exhibited significant differences in effective connectivity between 
Table 1. Statistical analysis

\begin{tabular}{|c|c|c|c|c|c|c|c|c|c|}
\hline Manuscript & Figure & Data type & Data structure & Type of test & $\begin{array}{l}\text { Multiple } \\
\text { comparison } \\
\text { correction }\end{array}$ & Program & Statistics & $p$ values & $\begin{array}{l}\text { Power/confidence } \\
\text { interval }\end{array}$ \\
\hline $\bar{a}$ & $3 A$ & $\begin{array}{l}\text { Number of } \\
\text { eye-blinks }\end{array}$ & Normal distribution & One-way repeated ANOVA & & $\mathrm{R}$ & $F_{(2,54)}=13.1814$ & $p<0.0001$ & $\eta_{\mathrm{g}}{ }^{2}=0.03540$ \\
\hline$b$ & & $\begin{array}{l}\text { Number of } \\
\text { eye-blinks }\end{array}$ & Normal distribution & $\begin{array}{l}t \text { test (post hoc } \\
\text { test, LIVE vs REST) }\end{array}$ & Bonferroni & $\mathrm{R}$ & $t_{(27)}=3.9464$ & $p=0.0015$ & $\begin{array}{c}\text { mean }=-1.2757 \\
(-1.9389 \\
\text { to }-0.6124)\end{array}$ \\
\hline c & & $\begin{array}{l}\text { Number of } \\
\text { eye-blinks }\end{array}$ & Normal distribution & $\begin{array}{l}t \text { test (post hoc } \\
\text { test, REPLAY vs REST) }\end{array}$ & Bonferroni & $\mathrm{R}$ & $t_{(27)}=3.8499$ & $p=0.0021$ & $\begin{array}{c}\text { mean }=-0.7946 \\
(-1.2182 \\
\text { to }-0.3711)\end{array}$ \\
\hline$d$ & & $\begin{array}{l}\text { Number of } \\
\text { eye-blinks }\end{array}$ & Normal distribution & $\begin{array}{l}t \text { test (post hoc } \\
\text { test, LIVE vs REPLAY) }\end{array}$ & Bonferroni & $\mathrm{R}$ & $t_{(27)}=2.3522$ & $p=0.0786$ & $\begin{array}{c}\text { mean }=-0.4810 \\
(-0.9006 \\
\text { to }-0.0614)\end{array}$ \\
\hline e & $3 B$ & Absolute $\Sigma N C R$ & Normal distribution & One-way repeated ANOVA & & $\mathrm{R}$ & $F_{(3,81)}=3.9830$ & $p=0.0295$ & $\eta_{\mathrm{g}}^{2}=0.03236$ \\
\hline f & & Absolute $\Sigma N C R$ & Normal distribution & $\begin{array}{l}\text { Paired } t \text { test (post hoc } \\
\text { test, LIVEFF vs REPLAYFF) }\end{array}$ & Bonferroni & $\mathrm{R}$ & $t_{(27)}=3.406$ & $p=0.0126$ & $\begin{array}{l}\text { mean }=1.2294 \\
\quad(0.4888-1.9700)\end{array}$ \\
\hline $\mathrm{g}$ & & Absolute $\Sigma N C R$ & Normal distribution & $\begin{array}{l}\text { Paired } t \text { test (post hoc } \\
\text { test, LIVEFF vs RESTFF) }\end{array}$ & Bonferroni & $\mathrm{R}$ & $t_{(27)}=1.4598$ & $p=0.9354$ & $\begin{array}{c}\text { mean }=0.8888 \\
\quad(-0.3604 \\
\text { to } 2.1379)\end{array}$ \\
\hline h & & Absolute $\Sigma N C R$ & Normal distribution & $\begin{array}{l}\text { Paired } t \text { test (post hoc } \\
\text { test, LIVEFF vs REPLAYSF) }\end{array}$ & Bonferroni & $\mathrm{R}$ & $t_{(27)}=3.2934$ & $p=0.0168$ & $\begin{array}{l}\text { mean }=1.0455 \\
\quad(0.3941-1.6969)\end{array}$ \\
\hline i & & Absolute $\Sigma N C R$ & Normal distribution & $\begin{array}{l}\text { Paired } t \text { test post hoc } \\
\text { test, REPLAYFF vs RESTFF }\end{array}$ & Bonferroni & $\mathrm{R}$ & $t_{(27)}=0.9065$ & $p=1.0000$ & $\begin{array}{c}\text { mean }=-0.3406 \\
(-1.1116 \\
\text { to } 0.4304)\end{array}$ \\
\hline j & & Absolute $\Sigma N C R$ & Normal distribution & $\begin{array}{l}\text { Paired } t \text { test post hoc } \\
\text { test, REPLAYFF vs REPLAYSF }\end{array}$ & Bonferroni & $\mathrm{R}$ & $t_{(27)}=1.2083$ & $p=1.0000$ & $\begin{array}{c}\text { mean }=-0.1838 \\
(-0.4960 \\
\text { to } 0.1284)\end{array}$ \\
\hline k & & Absolute $\Sigma N C R$ & Normal distribution & $\begin{array}{l}\text { Paired } t \text { test post hoc } \\
\text { test, RESTFF vs REPLAYSF }\end{array}$ & Bonferroni & $\mathrm{R}$ & $t_{(27)}=0.4349$ & $p=1.0000$ & $\begin{array}{c}\text { mean }=0.1568 \\
(-0.5829 \\
\text { to } 0.8965)\end{array}$ \\
\hline । & & Absolute $\Sigma N C R$ & Normal distribution & One-way repeated ANOVA & & $\mathrm{R}$ & $F_{(3,69)}=4.3334$ & $p=0.0074$ & $\eta_{\mathrm{g}}^{2}=0.0785$ \\
\hline $\mathrm{m}$ & & Absolute $\Sigma N C R$ & Normal distribution & $\begin{array}{l}\text { Paired } t \text { test (post hoc } \\
\text { test, LIVEFF vs REPLAYFF) }\end{array}$ & Bonferroni & $\mathrm{R}$ & $t_{(23)}=3.0965$ & $p=0.0306$ & $\begin{array}{l}\text { mean }=1.0291 \\
\quad(0.3416-1.7165)\end{array}$ \\
\hline $\mathrm{n}$ & & Absolute $\Sigma N C R$ & Normal distribution & $\begin{array}{l}\text { Paired } t \text { test (post hoc } \\
\text { test, LIVEFF vs RESTFF) }\end{array}$ & Bonferroni & $\mathrm{R}$ & $t_{(23)}=1.0783$ & $p=1.0000$ & $\begin{array}{c}\text { mean }=0.4588 \\
(-0.4214 \\
\text { to } 1.3390)\end{array}$ \\
\hline o & & Absolute $\Sigma N C R$ & Normal distribution & $\begin{array}{l}\text { Paired } t \text { test (post hoc } \\
\text { test, LIVEFF vs REPLAYSF) }\end{array}$ & Bonferroni & $\mathrm{R}$ & $t_{(23)}=3.0779$ & $p=0.0318$ & $\begin{array}{l}\text { mean }=0.7771 \\
(0.2548-1.2994)\end{array}$ \\
\hline $\mathrm{p}$ & & Absolute $\Sigma N C R$ & Normal distribution & $\begin{array}{l}\text { Paired } t \text { test post hoc } \\
\text { test, REPLAYFF vs RESTFF }\end{array}$ & Bonferroni & $\mathrm{R}$ & $t_{(23)}=1.9902$ & $p=1.0000$ & $\begin{array}{c}\text { mean }=-0.5702 \\
(-1.1630 \\
\text { to } 0.0225)\end{array}$ \\
\hline q & & Absolute $\Sigma N C R$ & Normal distribution & $\begin{array}{l}\text { Paired } t \text { test (post hoc } \\
\text { test, , REPLAYFF vs REPLAYSF }\end{array}$ & Bonferroni & $\mathrm{R}$ & $t_{(23)}=1.4744$ & $p=0.9234$ & $\begin{array}{l}\text { mean }=-0.2519 \\
\quad(-0.6054 \\
\text { to } 0.1015)\end{array}$ \\
\hline r & & Absolute $\Sigma N C R$ & Normal distribution & $\begin{array}{l}\text { Paired } t \text { test post hoc } \\
\text { test, REPLAYFF vs REPLAYSF }\end{array}$ & Bonferroni & $\mathrm{R}$ & $t_{(23)}=1.1336$ & $p=1.0000$ & $\begin{array}{c}\text { mean }=0.3183 \\
(-0.2626 \\
\text { to } 0.8992)\end{array}$ \\
\hline s & $3 C$ & Relative $\Sigma N C R$ & Normal distribution & One-way repeated ANOVA & & $\mathrm{R}$ & $F_{(2,54)}=10.3784$ & $p=0.0002$ & $\eta_{\mathrm{g}}^{2}=0.0483$ \\
\hline $\mathrm{t}$ & & $\begin{array}{l}\text { Relative } \\
\text { ¿NCR }\end{array}$ & Normal distribution & $\begin{array}{l}\text { Paired } t \text { test post hoc } \\
\text { test, LIVEFF vs REPLAYFF }\end{array}$ & Bonferroni & $\mathrm{R}$ & $t_{(27)}=3.4061$ & $p=0.0063$ & $\begin{array}{l}\text { mean }=1.2294 \\
\quad(0.4888-1.9700)\end{array}$ \\
\hline u & & Relative $\Sigma N C R$ & Normal distribution & $\begin{array}{l}\text { Paired } t \text { test post hoc } \\
\text { test, LIVEFF vs REPLAYSF }\end{array}$ & Bonferroni & $\mathrm{R}$ & $t_{(27)}=3.2934$ & $p=0.0084$ & $\begin{array}{l}\text { mean }=1.0455 \\
\quad(0.3941-1.6969)\end{array}$ \\
\hline v & & Relative $\Sigma$ NCR & Normal distribution & $\begin{array}{l}\text { Paired } t \text { test (post hoc } \\
\text { test, REPLAYFF vs RESTSF }\end{array}$ & Bonferroni & $\mathrm{R}$ & $t_{(27)}=1.2083$ & $p=0.7122$ & $\begin{array}{l}\text { mean }=-0.1838 \\
(-0.4960 \\
\text { to } 0.1284)\end{array}$ \\
\hline w & & Relative $\Sigma N C R$ & Normal distribution & One-way repeated ANOVA & & $\mathrm{R}$ & $F_{(2,40)}=7.9233$ & $p=0.0013$ & $\eta_{\mathrm{g}}^{2}=0.1330$ \\
\hline$x$ & & Relative $\Sigma N C R$ & Normal distribution & $\begin{array}{l}\text { Paired } t \text { test post hoc } \\
\text { test, LIVEFF vs REPLAYFF }\end{array}$ & Bonferroni & $\mathrm{R}$ & $t_{(20)}=2.8343$ & $p=0.0306$ & $\begin{array}{l}\text { mean }=7805 \\
\quad(0.0102-0.0250)\end{array}$ \\
\hline $\mathrm{y}$ & & Relative $\Sigma N C R$ & Normal distribution & $\begin{array}{l}\text { Paired } t \text { test (post hoc } \\
\text { test, LIVEFF vs REPLAYSF }\end{array}$ & Bonferroni & $\mathrm{R}$ & $t_{(20)}=2.9034$ & $p=0.0264$ & $\begin{array}{l}\text { mean }=0.8362 \\
\quad(0.0088-0.0167)\end{array}$ \\
\hline$z$ & & Relative $\Sigma N C R$ & Normal distribution & $\begin{array}{l}\text { Paired } t \text { test post hoc } \\
\text { test, REPLAYFF vs RESTSF }\end{array}$ & Bonferroni & $\mathrm{R}$ & $t_{(20)}=0.6790$ & $p=1.0000$ & $\begin{array}{c}\text { mean }=0.0558 \\
(-0.1156 \\
\text { to } 0.2271)\end{array}$ \\
\hline aа & & Absolute $\Sigma N C R$ & Normal distribution & $\begin{array}{l}\text { Repeated ANOVA, Main } \\
\text { effect of conditions }\end{array}$ & & $\mathrm{R}$ & $F_{(3,81)}=3.9830$ & $p=0.0106$ & $\eta_{\mathrm{g}}{ }^{2}=0.0132$ \\
\hline $\mathrm{bb}$ & & Absolute $\Sigma N C R$ & Normal distribution & $\begin{array}{l}\text { Repeated ANOVA, Main effect } \\
\text { of sessions }\end{array}$ & & $\mathrm{R}$ & $F_{(3,81)}=1.0351$ & $p=0.3816$ & $\eta_{\mathrm{g}}{ }^{2}=0.0139$ \\
\hline $\mathrm{cc}$ & & Absolute $\Sigma N C R$ & Normal distribution & $\begin{array}{l}\text { Repeated ANOVA, Interaction } \\
\text { (session } x \text { condition) }\end{array}$ & & $\mathrm{R}$ & $F_{(9,243)}=1.8235$ & $p=0.0647$ & $\eta_{\mathrm{g}}{ }^{2}=0.0128$ \\
\hline dd & 4 & $\begin{array}{l}\text { fMRI (BOLD } \\
\text { activation) }\end{array}$ & Normal distribution & Paired $t$ test (LIVE $>$ REPLAY) & $\begin{array}{l}\text { Random effect model at c } \\
\text { luster-level inference }\end{array}$ & SPM & & & \\
\hline ee & & $\begin{array}{l}\text { fMRI (BOLD } \\
\text { activation) }\end{array}$ & No assumption & Paired $t$ test (LIVE $>$ REPLAY) & $\begin{array}{l}\text { Nonparametric permutation test } \\
\text { at cluster-level inference } \\
\text { inued) }\end{array}$ & SnPM & & & \\
\hline
\end{tabular}


Table 1. Continued

\begin{tabular}{|c|c|c|c|c|c|c|c|c|c|}
\hline Manuscript & Figure & Data type & Data structure & Type of test & $\begin{array}{l}\text { Multiple } \\
\text { comparison } \\
\text { correction }\end{array}$ & Program & Statistics & $p$ values & $\begin{array}{l}\text { Power/confidence } \\
\text { interval }\end{array}$ \\
\hline $\mathrm{ff}$ & 5 & fMRI (PPI value) & Normal distribution & Paired $t$ test (LIVE $>$ REPLAY) & $\begin{array}{l}\text { Random effect model at } \\
\text { cluster-level inference }\end{array}$ & SPM & & & \\
\hline gg & & fMRI (PPI value) & No assumption & Paired $t$ test (LIVE $>$ REPLAY) & $\begin{array}{l}\text { Nonparametric permutation test } \\
\text { at cluster-level inference }\end{array}$ & SnPM & & & \\
\hline hh & 6 & $\begin{array}{l}\text { fMRI (normalized } \\
\text { interbrain sync) }\end{array}$ & Normal distribution & $\begin{array}{l}\text { Paired } t \text { test } \\
\qquad \text { (LIVE }>\text { REPLAY) }\end{array}$ & $\begin{array}{l}\text { Random effect model at } \\
\text { cluster-level inference }\end{array}$ & SPM & & & \\
\hline ii & & $\begin{array}{l}\text { fMRI (normalized } \\
\text { interbrain sync) }\end{array}$ & No assumption & $\begin{array}{l}\text { Paired } t \text { test } \\
\qquad \text { (LIVE }>\text { REPLAY) }\end{array}$ & $\begin{array}{l}\text { Nonparametric permutation test } \\
\text { at cluster-level inference }\end{array}$ & SnPM & & & \\
\hline
\end{tabular}

the LIVE and REPLAY conditions. Analyses were assessed at $p<0.05$ with FWE correction at the cluster level. The height threshold to form each cluster was set at an uncorrected $p$ value of 0.001 . This relatively high cluster-forming threshold is enough to prevent the failure of a multiplecomparison problem in cluster-level statistical inference (Eklund et al., 2016; Flandin and Friston, 2017). We also listed statistical values estimated by the SnPM toolbox with a nonparametric permutation test.

Interbrain synchronization analysis We tested for differences in the interbrain synchronization of the LIVE and REPLAY conditions using conventional voxel-to-voxel method used by previous hyperscanning fMRI studies that can identify interbrain synchronization of activation without any prior assumptions (Saito et al., 2010; Tanabe et al., 2012). We focused on the spontaneous fluctuation of BOLD signal that is unrelated to the task-related activation or deactivation (Fair et al., 2007). First, the taskrelated activation/deactivation was removed from the BOLD time series using the GLM model implemented in the SPM12. This yielded 3D-Nifti files representing residual time series that are independent of task-related activation/deactivation compared with baseline (i.e., the REST condition). Second, we divided the original time series into three sub-time series based on the experimental design: LIVE, REPLAY, and REST conditions. Third, we concatenated sub-time series into one long time series. The length of the LIVE- and REPLAY-related residual time series was 640 volumes. Next, we calculated the interbrain synchronization between the voxels representing the same MNI coordinates $(x, y, z)$ in the two participants using the Pearson's correlation coefficient. This computation was performed using a MATLAB script developed in-house. The correlation coefficient $r$ was transformed to the standardized $z$ score using Fisher's $r$-to- $z$ transformation. Finally, we obtained two 3D-Nifti images representing interbrain synchronization in the LIVE and REPLAY conditions per pair.

We conducted the random-effects model analysis in SPM12 at the group level. The normalized interbrain syn-
A

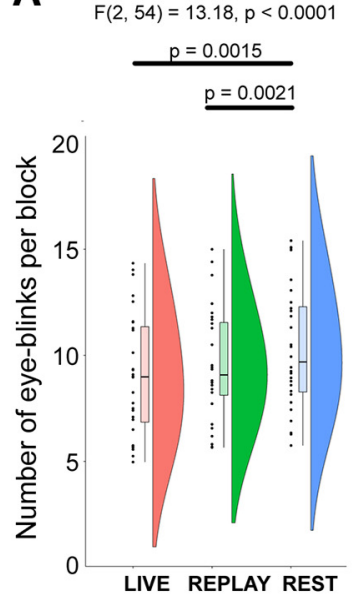

B
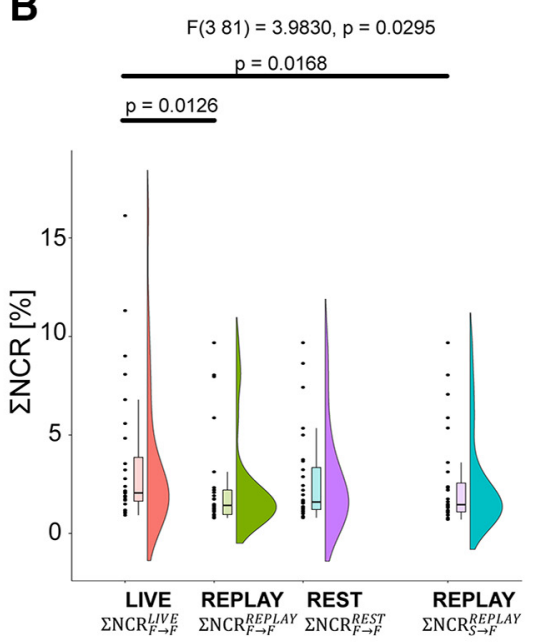

C
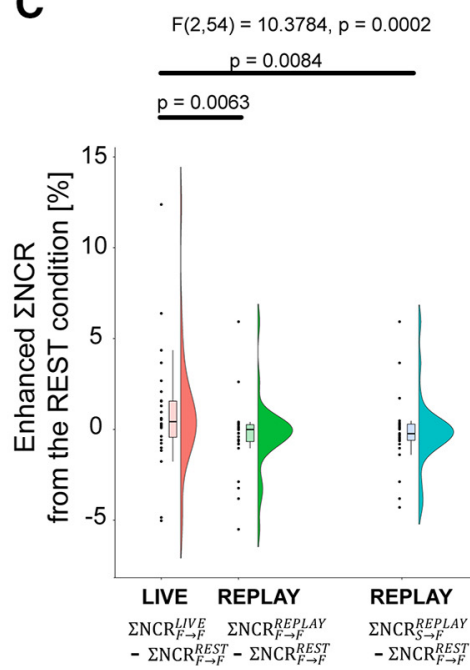

Figure 3. Behavioral analysis. $\boldsymbol{A}$, The number of eye-blinks per block. We omitted the first $5 \mathrm{~s}$ of each block because of instability of the recorded video induced by task switching; the number of eye-blinks was therefore calculated based on the succeeding $15 \mathrm{~s}$. Each dot represents a data point. In the boxplot, the line dividing the box represents the median of the data, the ends represent the upper/lower quartiles, and the extreme lines represent the highest and lowest values excluding outliers. $\boldsymbol{B}, \Sigma$ NCR values. The integral of the NCR of each condition across the whole frequency range was calculated. $\Sigma N C R_{F \rightarrow F}^{L / N E}$ is the $\Sigma N C R$ from the time series of the participant's facial movement to that of the partner during the LIVE condition. $\Sigma N \mathrm{NCR}_{F \rightarrow F}^{R E P L A Y}$ is the $\Sigma \mathrm{NCR}$ from the time series of the participant's facial movement to that of the partner during the REPLAY condition. $\Sigma N_{\text {NCR }}^{R E S T}$ is the $\Sigma N C R$ from the time series of the participant's facial movement to that of the partner during the REST condition. $\Sigma N N_{S \rightarrow F}^{R E P L A Y}$ is the $\Sigma N C R$ from the time series from the participant's delayed facial movement on the screen to the partner's time series during the REPLAY condition. $\boldsymbol{C}$, Enhanced $\Sigma$ NCR values from the REST condition. 
Table 2. Regions exhibiting greater activation in the LIVE condition than in the REPLAY condition

\begin{tabular}{|c|c|c|c|c|c|c|c|c|c|c|c|}
\hline \multicolumn{3}{|c|}{ Cluster level inference } & \multicolumn{3}{|c|}{ Peak level inference } & \multicolumn{6}{|c|}{ MNI coordinates } \\
\hline$P_{F W E}$ & & Cluster size & $P_{F W E}$ & & & & & & Side & Location & Probability \\
\hline \multirow[t]{2}{*}{0.015} & 0.025 & 2616 & 0.960 & 0.443 & 3.848 & -40 & -60 & -30 & L & Cerebellum & Lobule VIla crus I (Hem) (99\%) \\
\hline & & & 0.642 & 0.195 & 4.406 & -28 & -44 & -44 & $\mathrm{~L}$ & Cerebellum & \\
\hline \multirow[t]{3}{*}{0.010} & 0.022 & 2880 & 0.408 & 0.111 & 4.720 & -18 & -60 & -52 & $\bar{L}$ & Cerebellum & Lobule VIIIb (Hem) (68\%) \\
\hline & & & 0.846 & & 4.119 & -6 & -54 & -54 & L & Cerebellum & Lobule IX (Hem) (80\%) \\
\hline & & & 0.495 & 0.139 & 4.598 & 12 & -50 & -50 & $\mathrm{R}$ & Cerebellum & Lobule IX (Hem) $(87 \%)$ \\
\hline \multirow{3}{*}{0.002} & 0.014 & 4176 & 0.274 & 0.069 & 4.945 & -8 & 10 & 50 & $\mathrm{~L}$ & Pre-SMA & \\
\hline & & & 0.986 & 0.532 & 3.702 & -10 & 10 & 38 & $\mathrm{~L}$ & $\mathrm{ACC}$ & \\
\hline & & & 0.274 & 0.069 & 4.945 & 6 & 12 & 40 & $\mathrm{R}$ & $\mathrm{ACC}$ & \\
\hline \multirow[t]{2}{*}{0.056} & 0.040 & 1824 & 0.227 & 0.055 & 5.044 & -8 & -46 & -22 & $\mathrm{~L}$ & Cerebellum & \\
\hline & & & 0.463 & 0.127 & 4.641 & 0 & -56 & -26 & $\mathrm{R}$ & Cerebellum & Fastigial nucleus (37\%) \\
\hline
\end{tabular}

Hem, Hemisphere L, left; R, right. The $p$ values satisfying the statistical threshold $(p<0.05)$ after correcting for multiple comparisons ( $\mathrm{pFWE}$ ) are emphasized using bold type.

chronization images were used in the group-level analysis. Here, the paired $t$ test was used to test the differences in interbrain synchronization between the LIVE and REPLAY conditions. The resulting set of voxel values for each contrast constituted a statistical parametric map of the $t$ statistic (SPM $\{t\}$ ). The threshold for significance of the SPM $\{t\}$ was set at $p<0.05$ with FWE correction at the cluster level for the entire brain (Friston et al., 1996); the height threshold was set at an uncorrected $p$ value of 0.001 . This cluster threshold is conservative enough to prevent failure in cluster-level inference (Eklund et al., 2016; Flandin and Friston, 2017). The statistical inference was also estimated by a nonparametric permutation test using the SnPM toolbox, like the GLM and gPPI analyses. Anatomic labeling was based on Automated Anatomic Labeling (Tzourio-Mazoyer et al., 2002) and the Anatomy toolbox version 1.8 (Eickhoff et al., 2005). Final images have been displayed on a standard template brain image (http://www.bic.mni.mcgill.ca/ServicesAtlases/Colin27) using MRlcron (https://www.nitrc.org/ projects/mricron; Rorden and Brett, 2000).

\section{Results}

\section{Behavioral index}

Figure $3 A$ shows the average number of eye-blinks per block. Repeated-measures ANOVA revealed a significant effect of condition (Table 1, a; $F_{(2,54)}=13.1814, p<$ $\left.0.0001, \eta_{\mathrm{g}}{ }^{2}=0.0354\right)$. A post hoc comparison with Bonferroni correction revealed that there were no significant differences in the number of eye-blinks between the LIVE and REPLAY conditions (Table 1, $\mathrm{d}$; $t_{(27)}=2.3522, p=$ 0.0786 , Bonferroni correction), while the number of eyeblinks was greater in the REST condition than in the LIVE (Table 1, b; $t_{(27)}=3.9464, p=0.0015$, Bonferroni correction) and REPLAY (Table 1, c; $t_{(27)}=3.8499, p=0.0021$, Bonferroni correction) conditions.

Next, we compared the $\Sigma$ NCR values using repeatedmeasures ANOVA (Fig. 3B) and found a significant effect of condition was significant $\left(F_{(3,81)}=3.9830, p=0.0295\right.$, $\eta_{\mathrm{g}}{ }^{2}=0.03236$; Table 1, e). A post hoc comparison with Bonferroni correction revealed that there were significant differences between the $\Sigma N^{\prime} R_{F \rightarrow F}^{L I V E}$ and $\Sigma N_{F} R_{F \rightarrow F}^{R E P L Y Y}\left(t_{(27)}=\right.$ 3.406, $p=0.0126$; Table 1, f), $\Sigma N^{\prime} R_{F \rightarrow F}^{L I V E}$ and $\Sigma N C R_{S \rightarrow F}^{R E P L A Y}$ $\left(t_{(27)}=3.2934, p=0.0168\right.$; Table 1, h). Differences in the other pairs did not meet the threshold for statistical significance (Table 1, g, i, j, k). To confirm that the outliers did not skew the parametric statistics, we recomputed the statistical values after removing outliers defined by two SDs rather than 1.5. Four subjects to whom the outlier data could be attributed in at least one of the four conditions were excluded from the analysis; the repeatedmeasures ANOVA therefore included a sample of 24. Even after removing the outliers, the repeated-measures ANOVA could replicate the significant effect of condition $\left(F_{(3,69)}=4.3334, p=0.0074, \eta_{\mathrm{g}}{ }^{2}==0.0785\right.$; Table 1, $\left.\mathrm{l}\right)$, as well as the significant differences between the $\Sigma \mathrm{NCR}_{F \rightarrow F}^{L I V E}$ and $\Sigma \mathrm{NCR}_{F \rightarrow F}^{R E P L A Y}\left(t_{(23)}=3.0965, p=0.0306\right.$; Table 1, m), and between $\Sigma \mathrm{NCR}_{F \rightarrow F}^{L I V E}$ and $\Sigma \operatorname{NCR}_{S \rightarrow F}^{R E P L A Y}\left(t_{(23)}=\right.$ 3.0779, $p=0.0318$; Table 1, o). Differences in the other pairs did not meet the threshold for statistical significance (Table 1, n, p, q, r).

We also tested differences across enhanced $\Sigma$ NCR values using repeated-measures ANOVA (Fig. 3C) and found that the effect of condition was significant $\left(F_{(2,54)}=\right.$ 10.3784, $p=0.0002, \eta_{\mathrm{g}}{ }^{2}=0.03236$; Table 1, s). A post hoc comparison with Bonferroni correction revealed that there were significant differences between $\Sigma \mathrm{NCR}_{F \rightarrow F}^{L I V E}-\Sigma \mathrm{NCR}_{F \rightarrow F}^{R E S T}$ and $\Sigma \mathrm{NCR}_{F \rightarrow F}^{R E P L A Y}$ and $\Sigma \operatorname{NCR}_{F \rightarrow F}^{R E S T}\left(t_{(27)}=\right.$ 3.4061, $p=0.0063$; Table 1, t), as well as between $\Sigma N^{\prime} R_{F \rightarrow F}^{L I V E}-\Sigma N C R_{F \rightarrow F}^{R E S T}$ and $\Sigma N^{\prime} R_{S \rightarrow F}^{R E P L A Y}$ and $\Sigma \operatorname{NCR}_{F \rightarrow F}^{R E S T}\left(t_{(27)}=\right.$ 3.2934, $p=0.0084$; Table 1, u). Differences in the other pair did not meet the threshold for statistical significance (Table 1, v). We recalculated statistical inferences as raw NCR values without outliers to ensure that the outliers had no effect on the inferences. The stricter criteria for outliers remained 2 SDs, resulting in the removal of seven subjects from the analysis. Even after outliers were excluded from the analysis, we obtained qualitatively identical results: significant effect of condition $\left(F_{(2,40)}=7.9233, p=0.0013, \eta_{\mathrm{g}}{ }^{2}=\right.$ 0.1330; Table 1, w), and significant differences between $\Sigma N C R_{F \rightarrow F}^{L I V E}-\Sigma N C R_{F \rightarrow F}^{R E S T}$ and $\Sigma N^{R} R_{F \rightarrow F}^{R E P L A Y}-\Sigma N_{F} R_{F \rightarrow F}^{R E S T}\left(t_{(20)}=\right.$ 


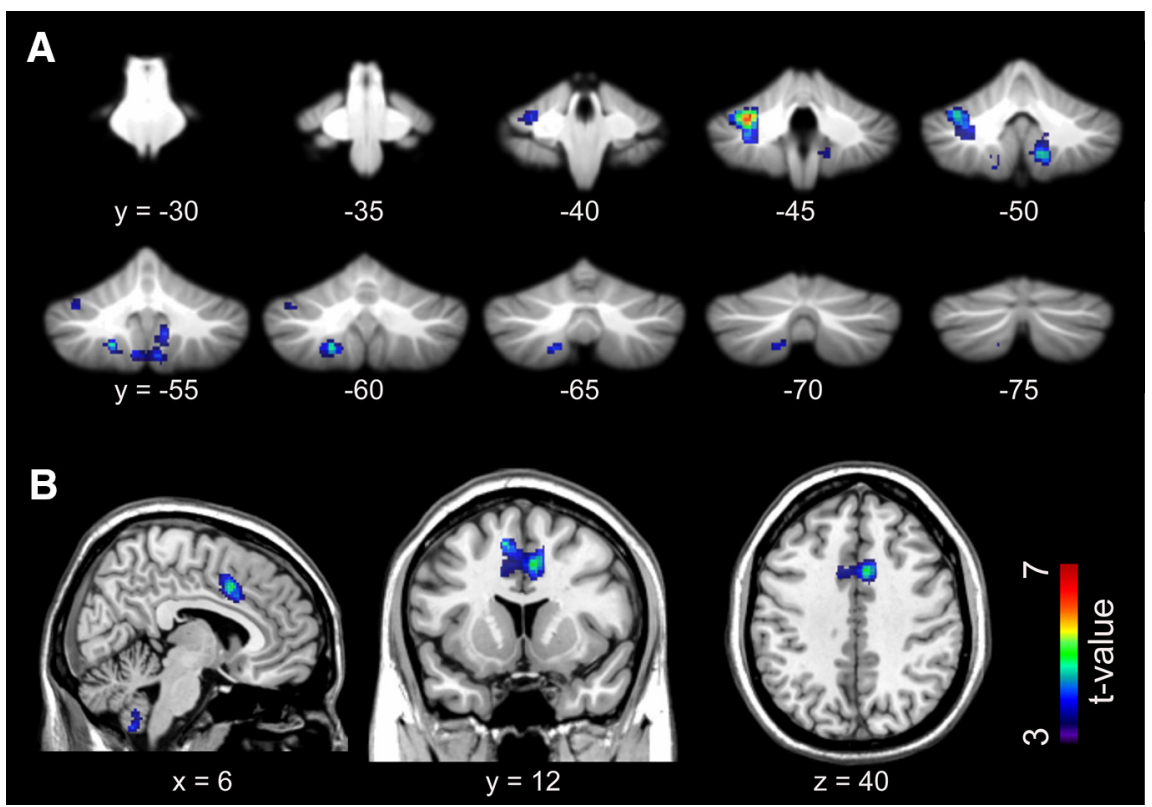

Figure 4. Brain regions exhibiting significantly greater activation in the LIVE condition than in the REPLAY condition. $\boldsymbol{A}$, Cerebellar activation is overlaid on the coronal planes of the SUIT template (Diedrichsen, 2006; Diedrichsen et al., 2009). B, The activation in the ACC is superimposed on the T1-weighted high-resolution anatomic MRI normalized to the MNI template space in the sagittal (left), coronal (middle), and transaxial (right) planes that crossed at $(6,12,40)$ in the MNI coordinate system (in mm). SUIT, Spatially unbiased infratentorial template.

2.8343, $p=0.0306$; Table 1, x) and between

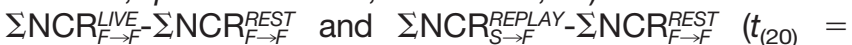
$2.9034, p=0.0265$; Table 1, y). Differences in other pairs did not meet the threshold for statistical significance (Table 1, z).

To test whether or not these enhancements of entrainment of eye-blinking is influenced by the number of blocks, we calculated the Akaike causality index for separate blocks of the experiment and applied the repeatedmeasures ANOVA ( 4 blocks $\times 4$ conditions) to the $\Sigma$ NCR data. We found a significant effect of conditions $\left(F_{(3,81)}=3.9830, p=0.0106, \eta_{\mathrm{g}}{ }^{2}=0.0132\right.$; Table 1, aa). However, the effects of sessions $\left(F_{(3,81)}=1.0351, p=\right.$ $0.3816, \eta_{\mathrm{g}}{ }^{2}=0.0139 ;$ Table 1, bb) and interaction (session $\times$ conditions; $F_{(9,243)}=1.8235, p=0.0647, \eta_{\mathrm{g}}{ }^{2}=$ 0.0128 ; Table 1, cc) were nonsignificant. Therefore, in the following analysis of neuroimaging data, we combined data from the four blocks.

\section{Brain activation in the LIVE and REPLAY conditions}

We used GLM analysis (Table 1, dd, ee) to elucidate brain activation in the LIVE and REPLAY conditions. For the LIVE versus REPLAY contrast, we observed greater activation in the left cerebellar hemisphere (lobules VI, VII, and VIIla), bilateral paravermis area (lobule XI; Fig. $4 A$ ), and the pre-supplementary motor area (SMA) extending to the dorsal tier of the anterior cingulate cortex (ACC; Fig. $4 B$ ). No significant differences in activation were observed in the REPLAY versus LIVE contrast. Detailed information regarding each cluster is outlined in Table 2.

\section{Results of the gPPI analysis}

The gPPI analysis (Table 1, ff, gg) revealed that the effective connectivity from the ACC region toward the dorsal anterior insular cortex (dAIC; Chang et al., 2013) was greater during the LIVE condition than during the REPLAY condition (Fig. 5, Table 3). No regions exhibited greater effective connectivity involving the pre-SMA-ACC regions in the REPLAY condition than in the LIVE condition. There was no modulation of effective connectivity involving cerebellar seed regions.

\section{Interbrain synchronization}

Figure 6 illustrates interbrain synchronization that is specific to the LIVE condition (Table 1, hh, ii). It was found on the bilateral middle occipital gyrus (MOG). Detailed information about these clusters is described in Table 4. No regions showed significant interbrain synchronization in the REPLAY condition compared with the LIVE condition.

\section{Discussion}

This study aimed to elucidate the behavioral and neural representations of mutual interaction during eye contact by comparing the neural activity associated with real-time eye contact with that associated with non-real-time eye contact. Our findings suggest that mutual interaction/ shared attention during eye contact is mediated by the cerebellum and the limbic mirror system.

\section{Behavioral index}

In this study, causal analysis using an MVAR model (Akaike, 1968; Ozaki, 2012) was performed to assess how an individual's temporal attentional window is influenced by that of the partner (Schippers et al., 2010; Okazaki et al., 2015; Leong et al., 2017). Our results show that participants were more sensitive to the eye-blinks of a 


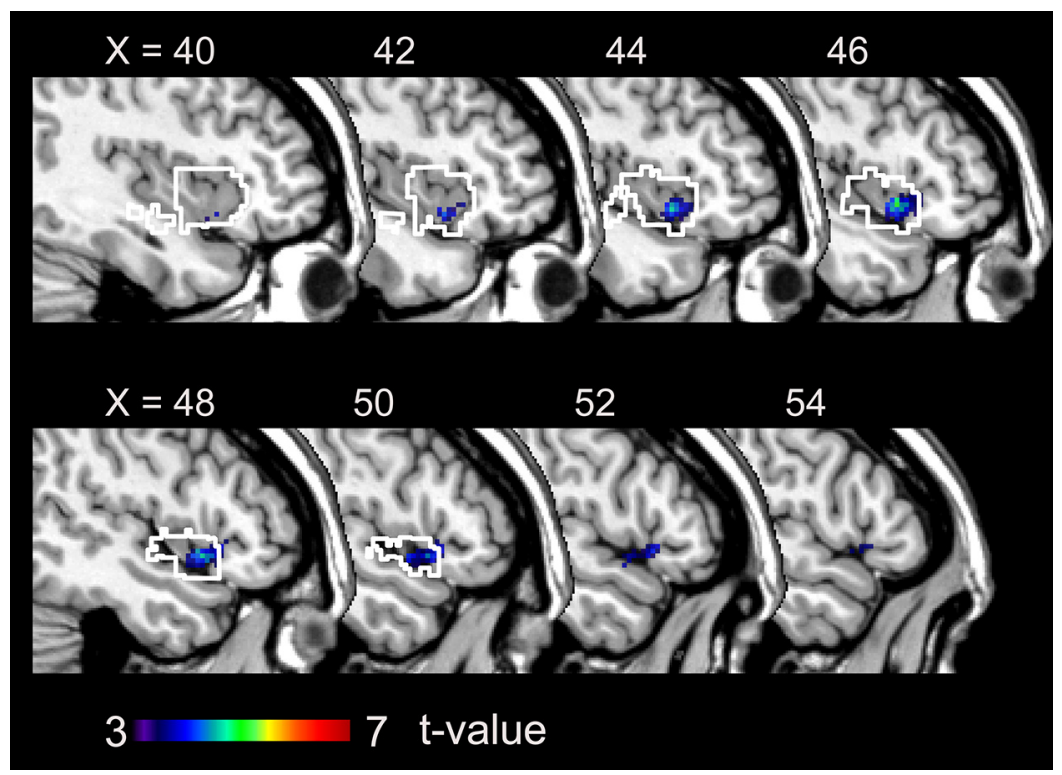

Figure 5. Regions exhibiting greater effective connectivity from the ACC in the LIVE condition than in the REPLAY condition. The area outlined in white is the dAIC (Chang et al., 2013). X indicates the MNI coordinates (in mm).

partner in the LIVE condition than in the REPLAY condition because none of the participants perceived the difference between the LIVE and REPLAY conditions. Thus, the experimental setup for our LIVE condition enabled a reciprocal feedback system through the visual modality. Our findings suggest that perceptual-motor interaction occurs during eye contact without conscious awareness. Previous researchers have argued that an essential component of real-time social interactions involves reciprocal coupling via perceptual-motor linkages between interacting individuals (Nicolis and Prigogine, 1977; Haken, 1983; Bernieri and Rosenthal, 1991; Strogatz, 2003; Oullier

Table 3. Regions exhibiting enhanced effective connectivity from the ACC in the LIVE condition

\begin{tabular}{|c|c|c|c|c|c|c|c|c|c|c|c|}
\hline \multicolumn{3}{|c|}{ Cluster level inference } & \multicolumn{3}{|c|}{ Peak level inference } & \multicolumn{3}{|c|}{ MNI coordinates } & \multirow[b]{2}{*}{ Side } & \multirow[b]{2}{*}{ Location } & \multirow[b]{2}{*}{ Probability } \\
\hline $\begin{array}{l}P_{\text {FWE }} \\
\text { SPM }\end{array}$ & SnPM & $\begin{array}{l}\text { Cluster size } \\
\left(\mathrm{mm}^{3}\right)\end{array}$ & $\begin{array}{l}P_{\text {FWE }} \\
\text { SPM }\end{array}$ & SnPM & $t$ value & $x$ & $y$ & $z$ & & & \\
\hline \multirow[t]{3}{*}{0.000} & 0.0824 & 1208 & 0.868 & 0.378 & 5.063 & 46 & 14 & -6 & $\mathrm{R}$ & Insula & \\
\hline & & & 1.000 & 1.000 & 3.545 & 54 & 14 & -4 & $\mathrm{R}$ & IFG & BA44 (21\%) \\
\hline & & & 1.000 & & 4.156 & 50 & 20 & -4 & $\mathrm{R}$ & IFGOr & BA45 (31\%) \\
\hline
\end{tabular}

IFG, Inferior frontal gyrus; IFGOr, Inferior frontal gyrus (pars opercularis); BA, Brodmann area; R, right. The $p$ values satisfying the statistical threshold ( $p<$ 0.05 ) after correcting for multiple comparisons (pFWE) are emphasized using bold type.

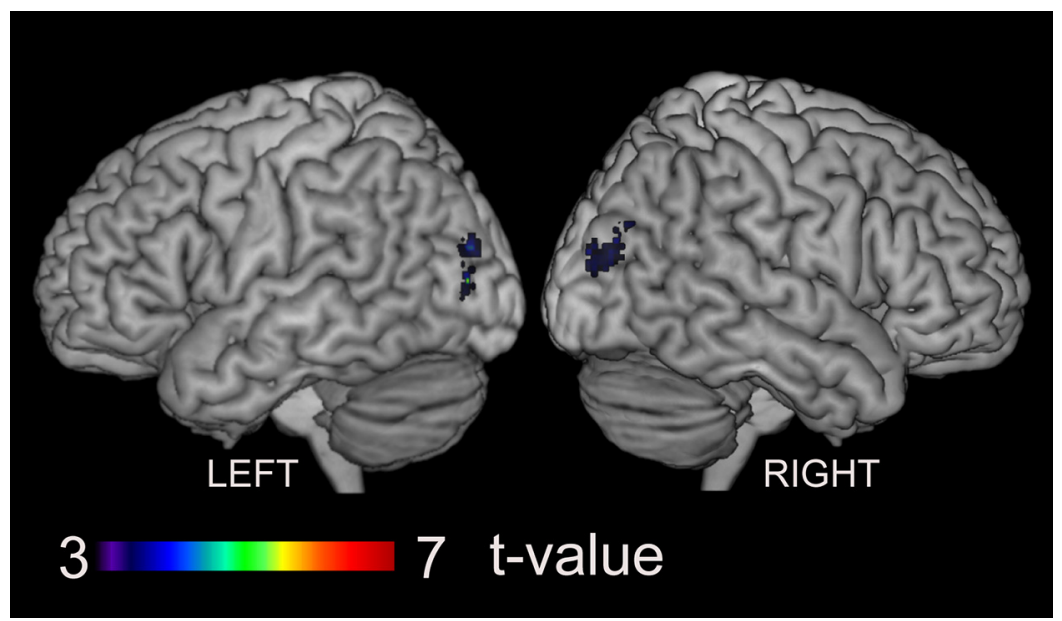

Figure 6. Regions exhibiting greater interbrain synchronization during the LIVE condition than the REPLAY condition. These areas are superimposed on a surface-rendered high-resolution anatomic MRI normalized to the MNI template viewed from the left and right. 
Table 4. The regions exhibiting enhanced interbrain synchronization in the LIVE condition compared with REPLAY condition

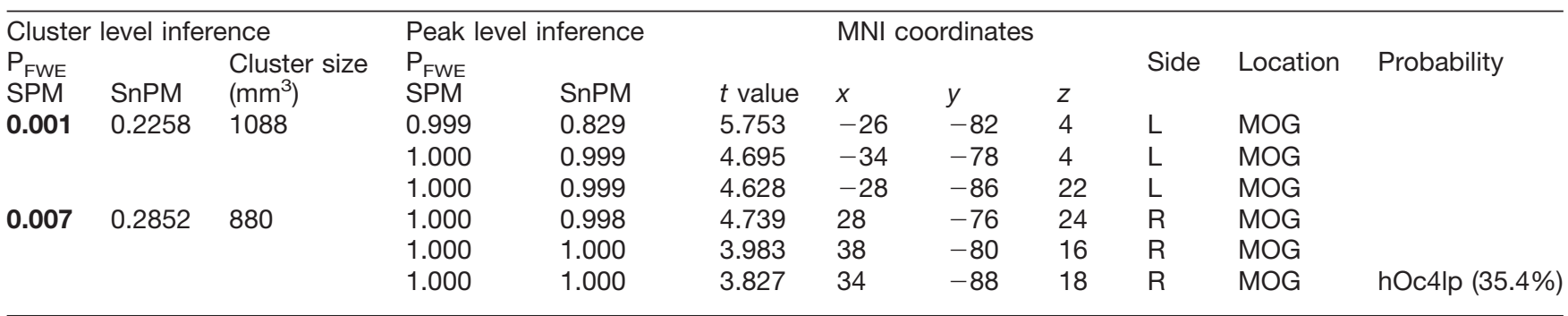

L, Left; R, right. The $p$ values satisfying the statistical threshold $(p<0.05)$ after correcting for multiple comparisons (pFWE) are emphasized using bold type.

et al., 2008). Our results extend this notion to the attention mediated by the minimal motion of blinking, which represents the temporal window of attention toward one's partner. Interestingly, the influence from a partner was significantly greater when the information flow between two individuals was reciprocal $\left(\Sigma N \mathrm{NR}_{F \rightarrow F}^{L / N E}\right)$ than when it was unidirectional $\left(\sum N C R_{S \rightarrow F}^{R E P L A Y}\right)$. As the mutual interaction in real time evinced a significant effect on the partner's eye-blink, this finding indicated that the mutual on-line interaction is critical to the influence of the other's eyeblink. Feedback through the on-line mutual interaction may induce a nonlinear response, causing the subtle effect to be amplified (Okazaki et al., 2015).

This experiment can be regarded as a simplified version of the social contingency detection task originally reported by Murray and Trevarthen (1985). Social contingency is defined as the cause-effect relationship between one's behavior and consequent social events (Gergely, 2001; Nadel, 2002) and is highly associated with a sense of self or one's own body in infancy, developing a sense of reciprocity, and participation with others (Rochat, 2001), all of which are critical for typical development (Mundy and Sigman, 1989; Gergely, 2001; Goldstein et al., 2003; Kuhl et al., 2003; Watanabe, 2013). Several previous studies have investigated differences in motherinfant interactions between real-time bidirectional interaction and off-line unidirectional interaction (Murray and Trevarthen, 1985; Nadel, 2002; Stormark and Braarud, 2004; Soussignan et al., 2006). Even in adults, turn-taking behavior accompanying social contingency is likely to serve as experience sharing, which represents the basis of all social behaviors (Rochat et al., 2009; Stevanovic and Peräkylä, 2015). Our results indicate that even a minimal task condition, such as mutual gaze, constitutes a reciprocal feedback system that can provide a basis for the detection of social contingency, promoting sharing of attention between partners (Farroni et al., 2002; Schilbach, 2015).

\section{Neural substrates of eye contact in real time}

Using a conventional GLM approach, we observed LIVE-specific activation in the cerebellum and ACC. The cerebellum plays a key role in error detection and processing of temporal contingency (Blakemore et al., 2003; Trillenberg et al., 2004; Matsuzawa et al., 2005), the latter of which is critical for real-time social communication (Gergely and Watson, 1999). The cerebellum is also critically involved in sensorimotor prediction (Blakemore and
Sirigu, 2003), especially in building predictions about the actual sensory consequences of an executed motor command. One previous fMRI study reported that the prediction error caused by sensory feedback is essential for acquiring internal forward models of movement control (Imamizu et al., 2000). This prediction (forward model) is mainly used in the early stages of movement execution to maintain accurate performance in the presence of sensory feedback delays (Wolpert and Kawato, 1998), as well as in social interaction (Wolpert et al., 2003). Considering that real-time social interaction can be regarded as a cross-individual sensorimotor loop (Wolpert et al., 2003; Froese and Fuchs, 2012), the cerebellum may receive visual afferents of the partner's blink as sensory feedback for the prediction of one's blink movement, to evaluate temporal contingency between the partners' blinks.

In humans, the ACC is located in the medial wall of the cerebral hemisphere, adjacent to the pre-SMA (Habas, 2010). The ventral (limbic) tier occupies the surface of the cingulate gyrus, corresponding to Brodmann's areas 24a and $24 \mathrm{~b}$, and subcallosal area 25. The dorsal (paralimbic) tier is buried in the cingulate sulcus, corresponding to Brodmann's areas 24c and 32 (for review, see Paus, 2001). The dorsal tier is involved in volitional motor control (Deiber et al., 1996; Picard and Strick, 1996; Brázdil et al., 2006).

The ACC and cerebellum constitute a tightly connected corticocerebellar network. Recent functional connectivity analysis studies have demonstrated that distinct cerebellar seed regions in the anterior portion of the crus I exhibit functional connectivity with the dorsolateral prefrontal cortex, the rostral portion of the inferior parietal lobule, and a frontal midline region bordering the pre-SMA and ACC in healthy adults (Buckner et al., 2011; Riedel et al., 2015). Conversely, the ACC exhibits a negative correlation with the cerebellum (Margulies et al., 2007), possibly reflecting its hypothesized role in the inhibition of prepotent stereotyped responses (Paus et al., 1993; Paus, 2001). In terms of anatomic connectivity, Zalesky et al. (2014) used diffusion MRI to demonstrate disruption of WM connectivity between the cerebellum and the cingulate cortex in individuals with Friedreich ataxia, an autosomal recessive disease involving degeneration of the spinal cord and cerebellum, thereby supporting the notion of reverse cerebellar diaschisis (Schmahmann and Sherman, 1998).

The corticocerebellar-thalamocortical circuit involving the cerebellum and ACC plays a role in attention. The cerebellum is involved in attention, including anticipation/prediction 
of the internal conditions for a particular operation, as well as the setting of specific conditions in preparation for that operation (Allen et al., 1997; Schweizer et al., 2007). Honey et al. (2005) reported that patients with schizophrenia exhibited an attenuated response of the ACC and cerebellum to degradation of the target during a continuous performance task, paralleling their limited visual attentional resources. They also observed disruption in the pattern of task-related connectivity of the ACC to the prefrontal regions. Honey et al. (2005) concluded that attentional impairments associated with schizophrenia could be attributed to the corticocerebellar-thalamocortical circuit, which includes the ACC and cerebellum. Considering the role of the ACC and cerebellum in sensorimotor and attentional control, the ACCcerebellar network may constitute a reactive-predictive controller system (Noy et al., 2011) by which one's own attention-contingent motor output (that is, eye-blink) is modulated by the visual input of the partner's movement. Under the mirror configuration during the LIVE condition, the reactive-predictive controllers in two individuals work to coordinate their own behavior with the partner's. Thus, it closes the sensorimotor circuits across the individuals.

\section{Enhanced connectivity between the ACC and AIC}

We observed enhanced effective connectivity from the ACC to the right $\mathrm{dAIC}$ in the LIVE condition than in the REPLAY condition. In the present study, no emotional processes were included in the task, suggesting that the enhancements in connectivity were related to recurrent interaction via eye contact. The ACC has a strong connection to the AIC (Margulies et al., 2007; Ghaziri et al., 2015), most prominently in the dAIC (Chang et al., 2013), a central hub in which several different cognitive networks converge (Dosenbach et al., 2006; Chang et al., 2013). The ACC-AIC network represents the portion of the limbic mirror system related to the recognition of affective behavior (Singer et al., 2004; Fabbri-Destro and Rizzolatti, 2008; Cattaneo and Rizzolatti, 2009).

Medford and Critchley (2010) proposed that the AIC and ACC represent the basis of self-awareness by constituting the input (AIC) and output (ACC) components of a system. In such a system, the integrated awareness of cognitive, affective, and physical states first generated by the integrative functions of the AIC are then rerepresented in the ACC as a basis for the selection of and preparation for responses to inner or outer events. Craig (2009) regarded the AIC as the probable site for awareness, based on its afferent representation of "feelings" from the body, and the ACC as the probable site for the initiation of behaviors. Meltzoff (2005) proposed a "likeme" framework for the understanding of others. He suggested that imitation enables the understanding of another mind based on an understanding of actions and their underlying mental states. Singer et al. (2004) observed that pain empathy relies on neural structures that are also involved in the direct experience of that emotion [i.e., the limbic mirror system (ACC, AIC)]. This finding is consistent with the Simulation Theory, which proposes that "we understand other people's minds by using our mental states to simulate how we might feel or what we might think in a given situation" (Lamm and Singer, 2010). Lamm and Singer (2010) concluded that perceiving the states of another activates neural representations encoding each state when it is experienced personally. In the eye-contact state, participants are aware that they are attending to their partner during eye contact. Therefore, given that the ACC-AIC network represents self-awareness, its activation during realtime eye contact may represent a shared mental state (i.e., awareness involving the participant and partner) such as shared attention. This interpretation is consistent with a study by Hietanen et al. (2008), which demonstrated that autonomic arousal is enhanced by eye contact with a live human, but not with static images of faces. The authors argued that this might be due to the enhancement of selfawareness by the presence of another person. The results of our study suggest that the self-awareness is enhanced by the social contingency generated with live humans through the interaction of each other's attentional windows via eyeblinks and that the regulation of self-awareness by interaction might be caused by the cerebellar-cerebral networks that tap into the limbic mirror system.

\section{Interbrain synchronization}

By comparing the degree of interbrain synchronization between the LIVE and REPLAY conditions, we found an enhancement in the MOG region related to the LIVE condition. This region is in the lateral occipitotemproral cortex (LOTC) and is almost identical to the region that shows interbrain synchronization specific to the eye-contact state (Koike et al., 2016). Previous studies suggest that the LOTC receives both sensory inputs of a partner's behavior (Lingnau and Downing, 2015) and efference copies of one's own behavior (Astafiev et al., 2004; Orlov et al., 2010). Therefore, the roles of the LOTC in supporting action perception and overt action performance are closely related. The LOTC may play a role in the human action observation network (Caspers et al., 2010) that is typically attributed to the frontoparietal mirror system (Oosterhof et al., 2013). Thus, the MOG region may conceivably receive information about self and other's eyeblinks.

Based on the electroencephalography (EEG) hyperscanning experiment of the mutual gaze between mothers and infants, Leong et al. (2017) found interpersonal neural synchronization. They argued that the phase of cortical oscillations reflects the excitability of underlying neuronal populations to incoming sensory stimulation (Schroeder and Lakatos, 2009), a possible mechanism for temporal sampling of the environment (Giraud and Poeppel, 2012). Interpersonal neural synchronization could increase within a dyad during the course of social interaction because each partner is continuously producing salient social signals (e.g., gaze) that act as synchronization triggers to reset the phase of his or her partner's ongoing oscillations (Leong et al., 2017). The present study showed neural synchronization in the LOTC, which receives both visual input of others' actions and efference copies of one's own actions. The salient social signals were sent to the partner through gaze or blink (defining the temporal attentional window), and the motor command corresponding to 
which is likely delivered to the LOTC as an efference copy. The eye-blink may, thus, act as a synchronization trigger. Therefore, the cross-individual neural synchronization of the MOG represents the alignment of the temporal pattern of attention, which may optimize communicative efficiency (Leong et al., 2017).

\section{Limitations and future directions}

The present study is subject to several limitations. First, concerning the hyperscanning fMRI experimental design, the very long mutual gaze condition was not ecological and may be quite different from conceptions of "mutual gaze" or "eye contact" informed by daily life. This is due to our use of a blocked design, the most effective way to detect brain activation. Also, the product of our experimental design, estimations of the temporal dynamics of eye-blink entrainment, brain activation, and interbrain synchronization, could not be performed. While we could not find a significant effect of session on the eye-blink entrainment in real-time eye contact, it is possible that the eye-blinking entrainments only occur in the very first phase of mutual gaze condition in one block. By refining the experimental and analytical design, we may further gain insight into the dynamics of interindividual interaction through eye-contact and interbrain synchronization. To explore the temporal dynamics of interbrain synchronization, we are currently conducting a hyperscanning simultaneous EEG-fMRI recording that could integrate the merits of the two neuroimaging methods (Koike et al., 2015). As the present study demonstrated the efficacy of using Akaike causality analysis to evaluate dynamic mutual interaction, future studies applying this method to EEG data in ecological settings of normal and diseased populations are warranted.

The present study is also limited by its capacity to find interbrain synchronization only between homologous regions, but not between nonhomologous regions (i.e., frontoparietal synchronization; Dumas et al., 2010). In our setting, two participants play identical roles in eye-to-eye communication; therefore, the resonance through interbrain closed loop might occur in the homologous regions. However, the interbrain effect may also occur between nonhomologous regions. To explore this possibility, an $\mathrm{ROI}$ analysis based on the precise parcellation of human cerebral cortex in a human connectome project may be the most suitable (Glasser et al., 2016). Future studies adapting this method could reveal the mechanism underlying the means by which two brains are wired through eye-to-eye communication without any conscious awareness.

\section{Summary}

In the present hyperscanning fMRI study, we focused on real-time mutual interaction during eye contact. The open-and-close timing of the attentional window, defined by eye-blinks, was entrained to that of the counterpart during real-time mutual interaction. Our findings indicate that the social interaction is nonlinear, and the influence from the partner might be amplified by the nonlinearity during the real-time interaction. Corresponding with the nonlinearly amplified behavioral coordination, real-time interaction during eye contact was found to be mediated by the amplified activation of the cerebellum and the cingulate motor cortex. This was accompanied by enhanced connectivity within the limbic mirror system. These findings underscore the notion that real-time eye contact generates an emergent property of shared attention, which is mediated by a cerebellocerebral network inclusive of the limbic mirror system.

\section{References}

Akaike $H$ (1968) On the use of a linear model for the identification of feedback systems. Ann Inst Stat Math 20:425-439. CrossRef

Allen G, Buxton RB, Wong EC, Courchesne E (1997) Attentional activation of the cerebellum independent of motor involvement. Science 275:1940-1943. CrossRef Medline

Allen M, Poggiali D, Whitaker K, Marshall TR, Kievit R (2018) Raincloud plots: a multi-platform tool for robust data visualization. PeerJ Preprints 6:e27137v1. CrossRef

Astafiev SV, Stanley CM, Shulman GL, Corbetta M (2004) Extrastriate body area in human occipital cortex responds to the performance of motor actions. Nat Neurosci 7:542-548. CrossRef Medline

Bernieri F, Rosenthal R (1991) Interpersonal coordination: behavior matching and interactional synchrony. In Fundamentals of nonverbal behavior (Feldman RS, Rime B, eds), pp 401-432. New York: Cambridge UP

Blakemore SJ, Sirigu A (2003) Action prediction in the cerebellum and in the parietal lobe. Exp Brain Res 153:239-245. CrossRef Medline

Blakemore SJ, Boyer P, Pachot-Clouard M, Meltzoff A, Segebarth C, Decety $J(2003)$ The detection of contingency and animacy from simple animations in the human brain. Cereb Cortex 13:837-844. CrossRef Medline

Brázdil M, Kuba R, Rektor I (2006) Rostral cingulate motor area and paroxysmal alien hand syndrome. J Neurol Neurosurg Psychiatry 77:992-993. CrossRef Medline

Buckner RL, Krienen FM, Castellanos A, Diaz JC, Yeo BTT (2011) The organization of the human cerebellum estimated by intrinsic functional connectivity. J Neurophysiol 106:2322-2345. CrossRef Medline

Calder AJ, Lawrence AD, Keane J, Scott SK, Owen AM, Christoffels I, Young AW (2002) Reading the mind from eye gaze. Neuropsychologia 40:1129-1138. CrossRef Medline

Caspers S, Zilles K, Laird AR, Eickhoff SB (2010) ALE meta-analysis of action observation and imitation in the human brain. Neuroimage 50:1148-1167. CrossRef Medline

Cattaneo L, Rizzolatti G (2009) The mirror neuron system. Arch Neurol 66:557-560. CrossRef Medline

Chang LJ, Yarkoni T, Khaw MW, Sanfey AG (2013) Decoding the role of the insula in human cognition: functional parcellation and largescale reverse inference. Cereb Cortex 23:739-749. CrossRef Medline

Chartrand TL, Van Baaren RB (2009) Human mimicry. Adv Exp Soc Psychol 41:219-274. CrossRef

Conty L, N'Diaye K, Tijus C, George N (2007) When eye creates the contact! ERP evidence for early dissociation between direct and averted gaze motion processing. Neuropsychologia 45:30243037. CrossRef Medline

Craig AD (2009) How do you feel-now? The anterior insula and human awareness. Nat Rev Neurosci 10:59-70. CrossRef Medline

Deiber MP, Ibañez V, Sadato N, Hallett M (1996) Cerebral structures participating in motor preparation in humans: a positron emission tomography study. J Neurophysiol 75:233-247. CrossRef Medline

Diedrichsen $J$ (2006) A spatially unbiased atlas template of the human cerebellum. Neuroimage 33:127-138. CrossRef Medline

Diedrichsen J, Balsters JH, Flavell J, Cussans E, Ramnani N (2009) A probabilistic MR atlas of the human cerebellum. Neuroimage 46: 39-46. CrossRef Medline 
Dosenbach NUF, Visscher KM, Palmer ED, Miezin FM, Wenger KK, Kang HC, Burgund ED, Grimes AL, Schlaggar BL, Petersen SE (2006) A core system for the implementation of task sets. Neuron 50:799-812. CrossRef Medline

Dumas G, Nadel J, Soussignan R, Martinerie J, Garnero L (2010) Inter-brain synchronization during social interaction. PLoS One 5:e12166. CrossRef Medline

Eickhoff SB, Stephan KE, Mohlberg H, Grefkes C, Fink GR, Amunts K, Zilles K (2005) A new SPM toolbox for combining probabilistic cytoarchitectonic maps and functional imaging data. Neuroimage 25:1325-1335. CrossRef Medline

Eklund A, Nichols TE, Knutsson H (2016) Cluster failure: why fMRI inferences for spatial extent have inflated false-positive rates. Proc Natl Acad Sci U S A 113:7900-7905. CrossRef Medline

Emery N (2000) The eyes have it: the neuroethology, function and evolution of social gaze. Neurosci Biobehav Rev 24:581-604. CrossRef Medline

Fabbri-Destro M, Rizzolatti G (2008) Mirror neurons and mirror systems in monkeys and humans. Physiology 23:171-179. CrossRef Medline

Fair D, Schlaggar B, Cohen A, Miezin F, Dosenbach NUF, Wenger KK, Fox MD, Snyder AZ, Raichle ME, Petersen SE (2007) A method for using blocked and event-related fMRI data to study "resting state" functional connectivity. Neuroimage 35:396-405. CrossRef

Farroni T, Csibra G, Simion F, Johnson MH (2002) Eye contact detection in humans from birth. Proc Natl Acad Sci U S A 99:96029605. CrossRef Medline

Flandin G, Friston KJ (2017) Analysis of family-wise error rates in statistical parametric mapping using random field theory. Hum Brain Mapp. Advance online publication. Retrieved November 1, 2017. doi: 10.1002/hbm.23839.

Franz VH, Loftus GR (2012) Standard errors and confidence intervals in within-subjects designs: generalizing Loftus and Masson (1994) and avoiding the biases of alternative accounts. Psychon Bull Rev 19:395-404. CrossRef Medline

Friston KJ, Holmes A, Poline JB, Price CJ, Frith CD (1996) Detecting activations in PET and fMRI: levels of inference and power. Neuroimage 4:223-235. CrossRef Medline

Friston KJ, Buechel C, Fink GR, Morris J, Rolls E, Dolan RJ (1997) Psychophysiological and modulatory interactions in neuroimaging. Neuroimage 6:218-229. CrossRef Medline

Friston KJ, Holmes AP, Worsley KJ (1999) How many subjects constitute a study? Neuroimage 10:1-5. CrossRef Medline

Friston KJ, Glaser DE, Henson RN, Kiebel S, Phillips C, Ashburner J (2002) Classical and Bayesian inference in neuroimaging: applications. Neuroimage 16:484-512. CrossRef Medline

Froese T, Fuchs T (2012) The extended body: a case study in the neurophenomenology of social interaction. Phenomenol Cogn Sci 11:205-235. CrossRef

George N, Driver J, Dolan RJ (2001) Seen gaze-direction modulates fusiform activity and its coupling with other brain areas during face processing. Neuroimage 13:1102-1112. CrossRef Medline

Gergely G (2001) The obscure object of desire: "Nearly, but Clearly Not, Like Me": contingency preference in normal children versus children with autism. Bull Menninger Clin 65:411-426. CrossRef Medline

Gergely G, Watson JS (1999) Early socio-emotional development: contingency perception and the social-biofeedback model. In: Early social cognition: understanding others in the first months of life (Rochat $\mathrm{P}$, ed), pp 101-136. Mahwah, NJ: Erlbaum.

Ghaziri J, Tucholka A, Girard G, Houde J-C, Boucher O, Gilbert G, Descoteaux M, Lippe S, Rainville P, Nguyen DK (2015) The corticocortical structural connectivity of the human insula. Cereb Cortex 27:1216-1228. CrossRef Medline

Giraud AL, Poeppel D (2012) Cortical oscillations and speech processing: emerging computational principles and operations. Nat Neurosci 15:511-517. CrossRef Medline

Glasser M, Coalson T, Robinson E, Hacker C, Harwell J, Yacoub E, Ugurbil K, Andersson J, Beckmann C, Jenkinson M, Smith S, Van
Essen D (2016) A multi-modal parcellation of human cerebral cortex. Nature 536:171-178. CrossRef Medline

Goldstein MH, King AP, West MJ (2003) Social interaction shapes babbling: testing parallels between birdsong and speech. Proc Natl Acad Sci U S A 100:8030-8035. CrossRef Medline

Habas C (2010) Functional connectivity of the human rostral and caudal cingulate motor areas in the brain resting state at 3T. Neuroradiology 52:47-59. CrossRef Medline

Haken H (1983) Advanced synergetics: instability hierarchies of selforganizing systems and devices. Berlin: Springer.

Hall A (1945) The origin and purposes of blinking. Br J Ophthalmol 29:445-467. CrossRef Medline

Hari R, Kujala M (2009) Brain basis of human social interaction: from concepts to brain imaging. Physiol Rev 89:453-479. CrossRef Medline

Herrmann A (2010) The interaction of eye blinks and other prosodic cues in German Sign Language. Sign Lang Linguist 13:3-39. CrossRef

Hietanen JK, Leppänen JM, Peltola MJ, Linna-Aho K, Ruuhiala HJ (2008) Seeing direct and averted gaze activates the approachavoidance motivational brain systems. Neuropsychologia 46: 2423-2430. CrossRef Medline

Honey GD, Pomarol-Clotet E, Corlett PR, Honey RAE, Mckenna PJ, Bullmore ET, Fletcher PC (2005) Functional dysconnectivity in schizophrenia associated with attentional modulation of motor function. Brain 128:2597-2611. CrossRef Medline

Imamizu H, Miyauchi S, Tamada T, Sasaki Y, Takino R, Pütz B, Yoshioka T, Kawato M (2000) Human cerebellar activity reflecting an acquired internal model of a new tool. Nature 403:192-195. CrossRef Medline

Kampe KKW, Frith CD, Frith U (2003) "Hey John": signals conveying communicative intention toward the self activate brain regions associated with "mentalizing," regardless of modality. J Neurosci 23:5258-5263. CrossRef Medline

Kawashima R, Sugiura M, Kato T, Nakamura A, Hatano K, Ito K, Fukuda H, Kojima S, Nakamura K (1999) The human amygdala plays an important role in gaze monitoring. Brain 122:779-783. CrossRef Medline

Koike T, Tanabe HC, Sadato N (2015) Hyperscanning neuroimaging technique to reveal the "two-in-one" system in social interactions. Neuroscience Research 90:25-32. CrossRef Medline

Koike T, Tanabe HC, Okazaki S, Nakagawa E, Sasaki AT, Shimada K, Sugawara SK, Takahashi HK, Yoshihara K, Bosch-Bayard J, Sadato N (2016) Neural substrates of shared attention as social memory: a hyperscanning functional magnetic resonance imaging study. Neuroimage 125:401-412. CrossRef Medline

Kuhl PK, Tsao F-M, Liu H-M (2003) Foreign-language experience in infancy: effects of short-term exposure and social interaction on phonetic learning. Proc Natl Acad Sci U S A 100:9096-9101. CrossRef Medline

Lamm C, Singer T (2010) The role of anterior insular cortex in social emotions. Brain Struct Funct 214:579-591. CrossRef Medline

Leong V, Byrne E, Clackson K, Georgieva S, Lam S, Wass S (2017) Speaker gaze increases information coupling between infant and adult brains. Proc Natl Acad Sci 114:13290-13295. CrossRef Medline

Lingnau A, Downing PE (2015) The lateral occipitotemporal cortex in action. Trends Cogn Sci 19:268-277. CrossRef Medline

Margulies DS, Kelly CAM, Uddin LQ, Biswal BB, Castellanos FX, Milham MP (2007) Mapping the functional connectivity of anterior cingulate cortex. Neuroimage 37:579-588. CrossRef Medline

Matsuzawa M, Matsuo K, Sugio T, Kato C, Nakai T (2005) Temporal relationship between action and visual outcome modulates brain activation: an fMRI study. Magn Reson Med Sci 4:115-121. CrossRef Medline

McLaren DG, Ries ML, Xu G, Johnson SC (2012) A generalized form of context-dependent psychophysiological interactions (gPPI): a comparison to standard approaches. Neuroimage 61:1277-1286. CrossRef Medline 
Medford N, Critchley HD (2010) Conjoint activity of anterior insular and anterior cingulate cortex: awareness and response. Brain Struct Funct 214:535-549. CrossRef Medline

Meltzoff AN (2005) Imitation and other minds: the "Like Me" hypothesis. In: Perspectives on imitation: from neuroscience to social science (Hurley S, Chater N eds), pp 55-77. Cambridge, MA: MIT.

Moeller S, Yacoub E, Olman CA, Auerbach E, Strupp J, Harel N, Uğurbil K (2010) Multiband multislice GE-EPI at 7 tesla, with 16-fold acceleration using partial parallel imaging with application to high spatial and temporal whole-brain FMRI. Magn Reson Med 63:1144-1153. CrossRef Medline

Morita T, Tanabe HC, Sasaki AT, Shimada K, Kakigi R, Sadato N (2014) The anterior insular and anterior cingulate cortices in emotional processing for self-face recognition. Soc Cogn Affect Neurosci 9:570-579. CrossRef Medline

Mundy P, Sigman M (1989) The theoretical implications of jointattention deficits in autism. Dev Psychopathol 1:173-183. CrossRef

Murray L, Trevarthen C (1985) Emotional regulation of interaction between 2-month-olds and their mothers. In: Social perception in infants. Field TM, Fox NA (eds), pp 177-197. Norwood.

Nadel $\mathrm{J}$ (2002) Imitation and imitation recognition: functional use in preverbal infants and nonverbal children with autism. In: The imitative mind: development evolution and brain (Meltzoff AN, Prinz W, eds), pp 42-62. Cambridge, UK: Cambridge UP.

Nakano T, Kitazawa S (2010) Eyeblink entrainment at breakpoints of speech. Exp Brain Res 205:577-581. CrossRef Medline

Nichols TE, Holmes AP (2002) Nonparametric permutation tests for functional neuroimaging: a primer with examples. Hum Brain Mapp 25:1-25. CrossRef Medline

Nicolis G, Prigogine IS (1977) Self-organization in nonequilibrium systems: from dissipative structures to order through fluctuations. New York: Wiley.

Noy L, Dekel E, Alon U (2011) The mirror game as a paradigm for studying the dynamics of two people improvising motion together. Proc Natl Acad Sci U S A 108:20947-20952. CrossRef Medline

Okazaki S, Hirotani M, Koike T, Bosch-Bayard J, Takahashi HK, Hashiguchi M, Sadato N (2015) Unintentional interpersonal synchronization represented as a reciprocal visuo-postural feedback system: a multivariate autoregressive modeling approach. PLoS One 10:e0137126. CrossRef Medline

Olejnik S, Algina J (2003) Generalized eta and omega squared statistics: measures of effect size for some common research designs. Psychol Methods 8:434-447. CrossRef Medline

Oldfield RC (1971) The assessment and analysis of handedness: the Edinburgh inventory. Neuropsychologia 9:97-113. CrossRef Medline

Orchard LN, Stern JA (1991) Blinks as an index of cognitive activity during reading. Integr Physiol Behav Sci 26:108-116. CrossRef Medline

Oosterhof NN, Tipper SP, Downing PE (2013) Crossmodal and action-specific: neuroimaging the human mirror neuron system. Trends Cogn Sci 17:311-318. CrossRef Medline

Orlov T, Makin TR, Zohary E (2010) Topographic representation of the human body in the occipitotemporal cortex. Neuron 68:586600. CrossRef Medline

Oullier O, de Guzman GC, Jantzen KJ, Lagarde J, Kelso JA (2008) Social coordination dynamics: measuring human bonding. Soc Neurosci 3:178-192. CrossRef Medline

Ozaki T (2012) Time-series modeling of neuroscience data. Boca Raton, FL: CRC.

Pageler NM, Menon V, Merin NM, Eliez S, Brown WE, Reiss AL (2003) Effect of head orientation on gaze processing in fusiform gyrus and superior temporal sulcus. Neuroimage 20:318-329. CrossRef Medline

Paus T (2001) Primate anterior cingulate cortex: where motor control, drive and cognition interface. Nat Rev Neurosci 2:417-424. CrossRef Medline

Paus T, Petrides M, Evans AC, Meyer E (1993) Role of the human anterior cingulate cortex in the control of oculomotor, manual, and speech responses: a positron emission tomography study. J Neurophysiol 70:453-469. CrossRef Medline

Pelphrey K, Viola R, McCarthy G (2004) When strangers pass: processing of mutual and averted social gaze in the superior temporal sulcus. Psychol Sci 15:598-603. CrossRef Medline

Picard N, Strick PL (1996) Motor areas of the medial wall: a review of their location and functional activation. Cereb Cortex 6:342-353. CrossRef Medline

Ponder E, Kennedy WP (1927) On the act of blinking. Q J Exp Physiol 18:89-110. CrossRef

Prochazkova E, Kret ME (2017) Connecting minds and sharing emotions through mimicry: a neurocognitive model of emotional contagion. Neurosci Biobehav Rev 80:99-114. CrossRef Medline

Riedel MC, Ray KL, Dick AS, Sutherland MT, Hernandez Z, Fox PM, Eickhoff SB, Fox PT, Laird AR (2015) Meta-analytic connectivity and behavioral parcellation of the human cerebellum. Neuroimage 117:327-342. CrossRef Medline

Rochat P (2001) Social contingency detection and infant development. Bull Menn Clin 65:347-360. CrossRef Medline

Rochat P, Passos-Ferreira C, Salem P (2009) Three levels of intersubjectivity in early development. In: Enacting intersubjectivity. Paving the way for a dialogue between cognitive science, social cognition and neuroscience (Carassa A, Morganti F, Rivaeds G, eds), pp 173-190. Lugano, Switzerland: Universita` della Svizzera Italiana.

Rorden C, Brett M (2000) Stereotaxic display of brain lesions. Behav Neurol 12:191-200. CrossRef Medline

Sato W, Kochiyama T, Yoshikawa S, Naito E, Matsumura M (2004) Enhanced neural activity in response to dynamic facial expressions of emotion: an fMRI study. Brain Res Cogn Brain Res 20:81-91. CrossRef Medline

Saito DN, Tanabe HC, Izuma K, Hayashi MJ, Morito Y, Komeda H, Uchiyama H, Kosaka H, Okazawa H, Fujibayashi Y, Sadato N (2010) "Stay tuned": inter-individual neural synchronization during mutual gaze and joint attention. Front Integr Neurosci 4:127. CrossRef Medline

Schilbach $L$ (2015) Eye to eye, face to face and brain to brain: novel approaches to study the behavioral dynamics and neural mechanisms of social interactions. Curr Opin Behav Sci 3:130-135. CrossRef

Schilbach L, Wohlschlaeger AM, Kraemer NC, Newen A, Shah NJ, Fink GR, Vogeley K (2006) Being with virtual others: neural correlates of social interaction. Neuropsychologia 44:718-730. CrossRef Medline

Schippers MB, Roebroeck A, Renken R, Nanetti L, Keysers C (2010) Mapping the information flow from one brain to another during gestural communication. Proc Natl Acad Sci U S A 107:93889393. CrossRef Medline

Schmahmann JD, Sherman JC (1998) The cerebellar cognitive affective syndrome. Brain 121:561-579. CrossRef Medline

Schroeder CE, Lakatos P (2009) Low-frequency neuronal oscillations as instruments of sensory selection. Trends Neurosci 32:9-18. CrossRef Medline

Schweizer TA, Alexander MP, Cusimano M, Stuss DT (2007) Fast and efficient visuotemporal attention requires the cerebellum. Neuropsychologia 45:3068-3074. CrossRef Medline

Sebanz N, Bekkering H, Knoblich G (2006) Joint action: bodies and minds moving together. Trends Cogn Sci 10:70-76. CrossRef Medline

Senju A, Johnson MH (2009) The eye contact effect: mechanisms and development. Trends Cogn Sci 13:127-134. CrossRef Medline

Singer T, Seymour B, O'Doherty J, Kaube H, Dolan RJ, Frith CD (2004) Empathy for pain involves the affective but not sensory components of pain. Science 303:1157-1162. CrossRef Medline

Soussignan R, Nadel J, Canet P, Gerardin P (2006) Sensitivity to social contingency and positive emotion in 2-month-olds. Infancy 10:123-144. CrossRef

Stern JA, Walrath LC, Goldstein R (1984) The endogenous eyeblink. Psychophysiology 21:22-33. CrossRef Medline 
Stevanovic M, Peräkylä A (2015) Experience sharing, emotional reciprocity, and turn-taking. Front Psychol 6:450. CrossRef Medline

Stormark KM, Braarud HC (2004) Infants' sensitivity to social contingency: a "double video" study of face-to-face communication between 2- and 4-month-olds and their mothers. Infant Behav Dev 27:195-203. CrossRef

Strogatz SH (2003) Sync: the emerging science of spontaneous order. New York: Hyperion.

Tanabe HC, Kosaka H, Saito DN, Koike T, Hayashi MJ, Izuma K, Komeda H, Ishitobi M, Omori M, Munesue T, Okazawa H, Wada Y, Sadato N (2012) Hard to "tune in": neural mechanisms of live face-to-face interaction with high-functioning autistic spectrum disorder. Front Hum Neurosci 6:268. CrossRef Medline

Trillenberg P, Verleger R, Teetzmann A, Wascher E, Wessel K (2004) On the role of the cerebellum in exploiting temporal contingencies: evidence from response times and preparatory EEG potentials in patients with cerebellar atrophy. Neuropsychologia 42:754-763. CrossRef Medline

Tzourio-Mazoyer N, Landeau B, Papathanassiou D, Crivello F, Etard O, Delcroix N, Mazoyer B, Joliot M (2002) Automated anatomical labeling of activations in SPM using a macroscopic anatomical parcellation of the MNI MRI single-subject brain. Neuroimage 15:273-289. CrossRef Medline
VanderWerf $F$, Brassinga $P$, Reits $D$, Aramideh $M$, Ongerboer de Visser B (2003) Eyelid movements: behavioral studies of blinking in humans under different stimulus conditions. J Neurophysiol 89: 2784-2796. CrossRef Medline

Watanabe K (2013) Teaching as a dynamic phenomenon with interpersonal interactions. Mind Brain Educ 7:91-100. CrossRef

Whitfield-Gabrieli S, Nieto-Castanon A (2012) Conn: a functional connectivity toolbox for correlated and anticorrelated brain networks. Brain Connect 2:125-141. CrossRef Medline

Wicker B, Keysers C, Plailly J, Royet JP, Gallese V, Rizzolatti G (2003) Both of us disgusted in my insula: the common neural basis of seeing and feeling disgust. Neuron 40:655-664. CrossRef Medline

Wolpert DM, Kawato M (1998) Multiple paired forward and inverse models for motor control. Neural Netw 11:1317-1329. CrossRef Medline

Wolpert DM, Doya K, Kawato M (2003) A unifying computational framework for motor control and social interaction. Philos Trans $\mathrm{R}$ Soc Lond B Biol Sci 358:593-602. CrossRef Medline

Zalesky A, Akhlaghi H, Corben LA, Bradshaw JL, Delatycki MB, Storey E, Georgiou-Karistianis N, Egan GF (2014) Cerebellocerebral connectivity deficits in Friedreich ataxia. Brain Struct Funct 219:969-981. CrossRef Medline 